\title{
Cerebellar Potentiation and Learning a Whisker-Based Object Localization Task with a Time Response Window
}

\author{
Negah Rahmati, ${ }^{1 \star}$ Cullen B. Owens, ${ }^{1 \star}$ Laurens W. J. Bosman, ${ }^{1 *}$ Jochen K. Spanke, ${ }^{1,2 *}$ Sander Lindeman, ${ }^{1}$ Wei Gong, ${ }^{1}$ \\ Jan-Willem Potters, ${ }^{1}$ Vincenzo Romano, ${ }^{1}$ Kai Voges, ${ }^{1}$ Letizia Moscato, ${ }^{1}$ Sebastiaan K. E. Koekkoek, ${ }^{1}$ Mario Negrello, ${ }^{1}$ \\ and Chris I. De Zeeuw ${ }^{1,2}$ \\ ${ }^{1}$ Department of Neuroscience, Erasmus MC, 3000 CA, Rotterdam, The Netherlands, and ${ }^{2}$ Netherlands Institute for Neuroscience, Royal Academy of Arts \\ and Sciences, $1105 \mathrm{BA}$, Amsterdam, The Netherlands
}

Whisker-based object localization requires activation and plasticity of somatosensory and motor cortex. These parts of the cerebral cortex receive strong projections from the cerebellum via the thalamus, but it is unclear whether and to what extent cerebellar processing may contribute to such a sensorimotor task. Here, we subjected knock-out mice, which suffer from impaired intrinsic plasticity in their Purkinje cells and long-term potentiation at their parallel fiber-to-Purkinje cell synapses (L7-PP2B), to an object localization task with a time response window (RW). Water-deprived animals had to learn to localize an object with their whiskers, and based upon this location they were trained to lick within a particular period ("go" trial) or refrain from licking ("no-go" trial). L7-PP2B mice were not ataxic and showed proper basic motor performance during whisking and licking, but were severely impaired in learning this task compared with wild-type littermates. Significantly fewer L7-PP2B mice were able to learn the task at long RWs. Those L7-PP2B mice that eventually learned the task made unstable progress, were significantly slower in learning, and showed deficiencies in temporal tuning. These differences became greater as the RW became narrower. Trained wild-type mice, but not L7-PP2B mice, showed a net increase in simple spikes and complex spikes of their Purkinje cells during the task. We conclude that cerebellar processing, and potentiation in particular, can contribute to learning a whisker-based object localization task when timing is relevant. This study points toward a relevant role of cerebellum-cerebrum interaction in a sophisticated cognitive task requiring strict temporal processing.

\section{Introduction}

Active touch by mystacial vibrissae forms a major source of sensory information for rodents (Carvell and Simons, 1990; Hartmann, 2009). Head-fixed mice can be trained to exploit such active exploration to associate the position of a stimulation bar in their whisker field with the availability of a water reward (O'Connor et al., 2010a,b). Whisker-based object localization has been shown to involve correlated neuronal activity in the barrel cortex (S1) and the whisker motor cortex (M1; Xu et al., 2012). However, it is unclear whether other brain regions also contribute to such tasks. Given the numerous brain regions involved in whisker control, and their intricate connections (Bosman et al.,

Received July 11, 2013; revised Dec. 24, 2013; accepted Dec. 29, 2013.

Author contributions: N.R., C.B.O., L.W.J.B., S.L., W.G., J.-W.P., S.K.E.K., and C.I.D.Z. designed research; N.R., S.L., W.G., and L.M. performed research; C.B.O., L.W.J.B., J.K.S., K.V., S.K.E.K., and M.N. contributed unpublished reagents/analytic tools; N.R., C.B.O., L.W.J.B., J.K.S., S.L., W.G., V.R., L.M., S.K.E.K., M.N., and C.I.D.Z. analyzed data; N.R., C.B.O., L.W.J.B., J.K.S., M.N., and C.I.D.Z. wrote the paper.

This research was supported by funds (to C.I.D.Z.) from the Dutch Organization for Medical Sciences, Earth and Life Sciences, Senter (NeuroBasic), and the ERC-adv, CEREBNET, and C7 programs of the European Community. We thank Dr. Karel Svoboda for help with the behavioral training and related apparatus; Kees Donkersloot, Froukje Zandstra, and Alex Brouwer for excellent technical support; and Dr. Jos van der Geest for advice on statistical analysis. We gratefully acknowledge using the BIOTACT Whisker Tracking Tool (http://bwtt.sourceforge.net) for tracking whisker movements.

${ }^{*} N$. R., C.B.O., L.W.J.B., and J.K.S. contributed equally to this work.

The authors declare no competing financial interests.

Correspondence should be addressed to Chris I. De Zeeuw, Department of Neuroscience, Erasmus MC, P.O. Box 2040, 3000 CA, Rotterdam, The Netherlands. E-mail: c.dezeeuw@erasmusmc.nl

DOI:10.1523/JNEUROSCI.2966-13.2014

Copyright $\odot 2014$ the authors $\quad 0270-6474 / 14 / 341949-14 \$ 15.00 / 0$
2011; Kleinfeld and Deschênes, 2011), one may expect other areas to also play a role in whisker-based object localization. Here we focus on the cerebellum, a region important for sensorimotor integration, central to the whisker system, and required for procedural learning and accurate timing of fine movements (Grodd et al., 2001; Bosman et al., 2010; De Zeeuw et al., 2011).

Purkinje cells are the sole output neurons of the cerebellar cortex. Their activity depends on both synaptic and intrinsic plasticity (Hansel et al., 2001; Ito, 2001; Gao et al., 2012). In the absence of calmodulin-activated protein phosphatase 2B (PP2B), both the enhancement of intrinsic excitability of Purkinje cells and long-term potentiation at the parallel fiber-to-Purkinje cell synapses are impaired, resulting in increased simple spike-firing regularity (Schonewille et al., 2010). Purkinje cell-specific PP2B knock-out (L7-PP2B) mice show deficits in motor learning and consolidation, as demonstrated during adaptation of the vestibulo-ocular reflex and eyeblink conditioning (Schonewille et al., 2010). To date, of all currently available cell-specific cerebellar mouse mutants that are not ataxic, the L7-PP2B mutant shows the most prominent deficits in procedural learning (De Zeeuw et al., 2011; Gao et al., 2012). Yet, when subjected to standard nonmotor tasks, like the Morris water maze, fear conditioning, or social interaction task in which no fine temporal control is required, the L7-PP2B mutants do not show abnormal performance (Galliano et al., 2013).

The primary objective of this study was to investigate whether, and if so to what extent, the potentiation of intrinsic activity and 
synaptic strength of Purkinje cells in the cerebellum is required for a localization task in which the response has to be given within an allotted response period following the insertion of a bar into the whisker field. To this end, we tested L7-PP2B mice using a modified version of the object localization task introduced by O'Connor et al. (2010a) while subsequently tightening temporal constraints of the response. We demonstrate that L7-PP2B mutants are severely impaired in learning this whisker-based object localization task. The cerebellar contribution to this learning task was further corroborated by electrophysiological recordings showing a net upregulation of Purkinje cell activity during trials in wild-type (WT) mice, but not in L7-PP2B mice. Thus, we show for the first time that this learning task can depend in part on plasticity and/or processing in the cerebellum when response timing is relevant.

\section{Materials and Methods}

The generation of mice lacking functional PP2B in their Purkinje cells has been described previously (Schonewille et al., 2010). Briefly, we used crossings of mice in which the gene for the regulatory subunit (CNB1) of PP2B was flanked by loxP sites (Zeng et al., 2001), with transgenic mice expressing Cre under control of the L7 promoter (Barski et al., 2000). L7-Cre ${ }^{+/-}-c_{b} 1^{\mathrm{f} / \mathrm{f}}$ mice (i.e., L7-PP2B mice) were compared with littermate controls (i.e., WT mice), consisting of L7-Cre ${ }^{-l-}-\mathrm{cnb} 1^{\mathrm{f} / \mathrm{f}}$ and L7$\mathrm{Cre}^{-/-}-\mathrm{cnb} 1^{+/+}$mice. All experimental procedures were approved by the institutional animal welfare committee, as required by Dutch law.

Licking behavior. Since licking behavior was used as the behavioral readout of the localization task (see below), we first assessed the overall performance during baseline licking in 10 female L7-PP2B mice and 9 female WT littermates that were $20-25$ weeks old. Baseline licking was measured in the home cages of naive mice by measuring threshold crossings in the junction potential between an aluminum floor plate and the spout of a normal drinking bottle with the use of an AD converter operating at a sample rate of $6 \mathrm{kHz}$ (RZ2, Tucker-Davis Technologies; Fig. $1 A)$. Our experimental design was based on that of the study by Hayar et al. (2006). Since mice normally lick very sparsely, they were deprived of water for $20 \mathrm{~h}$ before the period of experimental testing, which lasted $\sim 1$ h. We restricted our analysis of baseline performance to bouts of rhythmic licking, which were defined by the occurrence of at least two licks with a maximal interlick interval of $175 \mathrm{~ms}$ (Fig. 1A). Licking during the training paradigm was detected by laser beam crossings at the lickport. To avoid double detections, we used a dead time of $20 \mathrm{~ms}$.

Auto-correlograms with a bin width of $5 \mathrm{~ms}$ were made of the lick times in the home cage, as well as during the association task and the object localization task (see below). Side peaks were normalized to the center peak and detected as local maxima. The amplitude of these first side peaks was considered to be the strength of the rhythmicity. Rhythmic licking predominantly occurred at frequencies between 6 and $12 \mathrm{~Hz}$. Further quantitative analysis was performed in this frequency band. Licking was considered to be rhythmic if the first side peak exceeded the average \pm 3 SDs of the period between 1000 and 800 ms before each lick.

Whisking behavior. Since whisking behavior was used as the critical sensory detection mechanism for the localization task (see below), we also assessed the overall performance during free whisking in 11 adult female L7-PP2B and 10 adult female WT littermates (Fig. $1 E-I$ ). We decided to keep all whiskers intact. Spontaneous whisker movements in head-restrained mice were recorded with a high-speed video camera (full frame rate $1000 \mathrm{~Hz}$; A504k camera, Basler), using a red LED panel $(\lambda=$ $640 \mathrm{~nm}$ ) as backlight. In addition, videos were made during selected sessions of the training paradigm (see below; Figs. 2, 3, 4). The latter videos were recorded with a full frame rate of $160 \mathrm{~Hz}$ (piA640-210gm camera, Basler) and infrared lighting to avoid luminance of the training environment $(\lambda>900 \mathrm{~nm})$.

To establish the periods during which the mice actively moved their whiskers, we estimated whisker motion using the BlockMatcher function in Matlab (MathWorks). First, we selected a rectangular region of interest containing the proximal part of the whiskers. This region was sliced into a grid with rectangular blocks. Across contiguous frames, each block was transformed by a rotation and translation, such that the distance between the blocks in consecutive frames was minimized. The whisker motion was calculated as the Pythagorean addition of the translation and the rotation of all blocks (Fig. $1 F$ ). To validate the automated algorithms for both whisker motion periods, and for whisker angle and position tracking, we also tracked individual whiskers manually in 25 video fragments. This was done by marking in each frame the position of the follicle and the intersection of the whisker with a line parallel to the body axis at $\sim 1 \mathrm{~cm}$ lateral to the whisker pad. It turned out that the motion detection could reliably detect periods during which whisker movements occurred. The extent of whisker movements was further illustrated using SD projection plots of video fragments (ImageJ, National Institutes of Health). During the training paradigms, each video fragment reflected the activity during a single response window (RW; see below). Here we used pseudocolored SD projection plots to illustrate the whisker movements over time.

The outcome of the motion estimation algorithm was used to truncate the video files in time to process only those periods of the video files that show whisker motion (see below). To this end, the variability in the motion estimation result was evaluated with a sliding window approach that calculated the local SD of the signal. In a second step, this local SD signal was thresholded to identify periods of motion. During the periods in which the whisker moved, we tracked them automatically using the BIOTACT Whisker Tracking Tool (BWTT) with the sdGeneric, stShapeSpaceKalman, ppBigExtractionAndFiltering, and wdIgorMeanAngle plugins (http://bwtt.sourceforge.net; for details, see Perkon et al., 2011). Briefly, we first determined the position of the snout in each frame semiautomatically by fitting a template to the snout. After masking the snout and subtracting the unmoved background from each frame, the whiskers themselves were traced in a radial approach. The algorithm detected edges in the frame in consecutive concentric snout-shaped masks around the actual snout mask. Ultimately, we detected the start and end nodes of the fitted line segments, and calculated the angles of the whiskers from these values.

The final BWTT result provided us with the angles of all detected whiskers per video frame. To relate the angles across frames to the tracks, we wrote an algorithm that predicts track values in consecutive frames based on the position and velocity in the angular value as well as the $y$-position of the last video frames. The predicted track values for the next frame were compared with the detected values in the next frame and were assigned according to a minimum deviation approach between them (within reasonable bounds; Fig. $1 G$ )

The frequencies and amplitudes of individual whisking bouts were derived from the automatically tracked whisker movements. We defined a whisking bout as a period of at least three consecutive sweeps with a minimal amplitude of $10^{\circ}$. The frequency was derived from three consecutive sweeps, and the amplitude was defined as the difference between the rostral-most and caudal-most positions during these three sweeps. The tracked whisker was taken from the caudal half of all whisker tracks, preferably the caudal-most full track. The traces in Figures $3 D$ and $4 D$ were made from videos with a lower frame rate $(160 \mathrm{~Hz})$ and infrared illumination. To account for changes in the number of visible whiskers across frames (e.g., because of overlapping or merging with the snout mask during a retraction), we discarded the whiskers with positions $>75 \%$ and $<25 \%$ of the position distribution, which tend to disappear from the frame, thereby keeping the ones close to the center of the whisker field. In each frame, the whisker position distributions were calculated from the cumulative distribution of whisker positions derived from 10 frames before and after the frame of interest.

Habituation and association stage. We prepared 14 female L7-PP2B mice and 16 female WT littermate controls, all of which were 20-25 weeks of age and carried a body weight of $22-25 \mathrm{~g}$, for behavioral testing. These mice received a magnetic pedestal that was attached to the skull above bregma using Optibond adhesive (Kerr Corporation) under isoflurane anesthesia $\left(2-4 \% \mathrm{v} / \mathrm{v}\right.$ in $\left.\mathrm{O}_{2}\right)$. Postsurgical pain was treated with 5 $\mathrm{mg} / \mathrm{kg}$ carprofen (Rimadyl, Pfizer) and $5 \mathrm{mg}$ of lidocaine (Braun). After $2 \mathrm{~d}$ of recovery, mice were put on water restriction $(1 \mathrm{ml} / \mathrm{d})$, while food was available ad libitum. On the fourth, fifth, and sixth days of water restriction, mice were put in a head-fixed position using the magnetic 
A
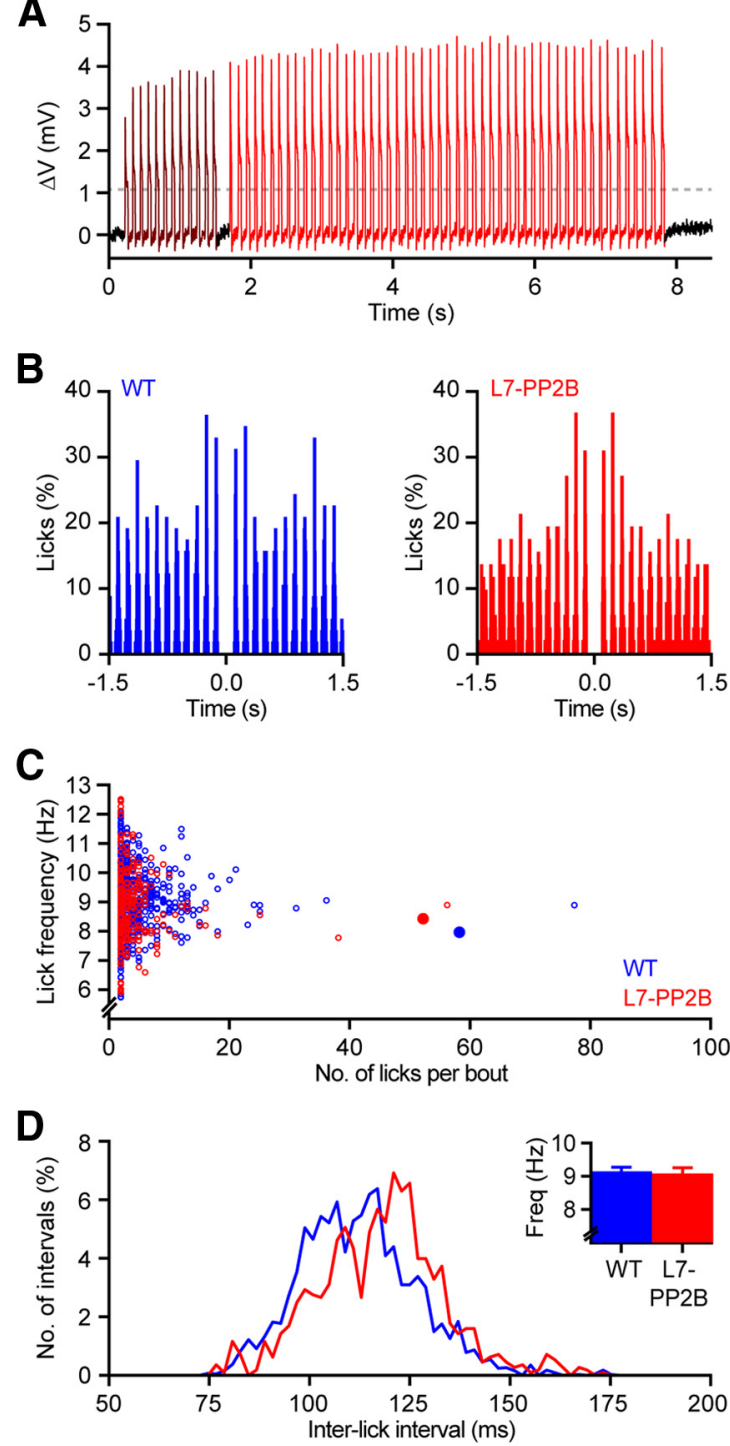

$\mathbf{E}$
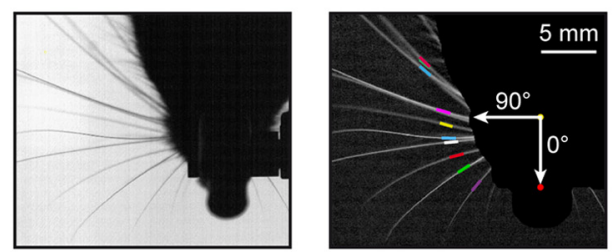

$\mathbf{F}$

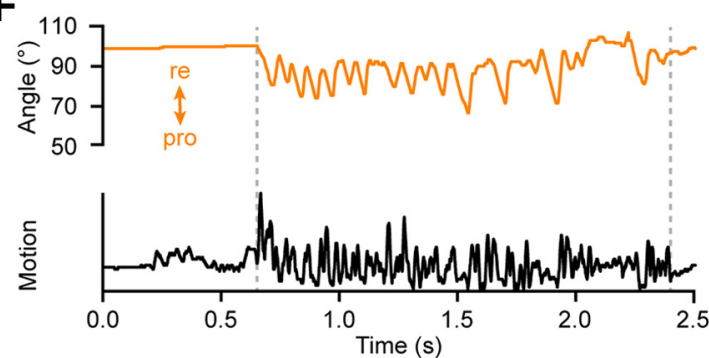

G

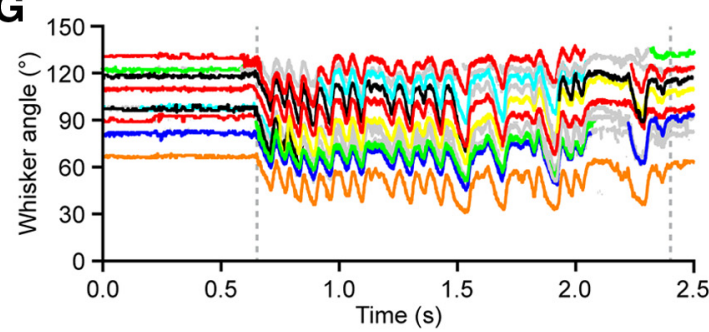

H

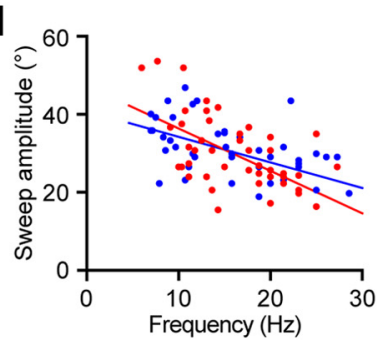

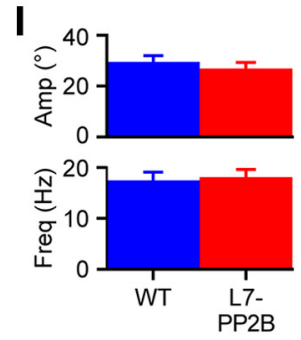

Figure 1. L7-PP2B mice do not have motor deficits preventing normal rhythmic licking and whisking. A, A period of rhythmic licking in a freely moving L7-PP2B mouse. Licks can be seen as positive deflections of the junction potential between the spout of the drinking bottle and an aluminum floor plate in the home cage. This licking period consisted of two individual licking bouts, as indicated by two colors. The dashed line indicates the threshold used for automated lick detection. B. Auto-correlograms of licking bouts in a WT mouse (left) and an L7-PP2B mouse (right). The right panel is the auto-correlogram of the second licking bout (depicted in red) in $A$. The bins were normalized with respect to the center bin that was removed to improve visibility. C, Both WT and L7-PP2B mice displayed short and long licking bouts with lick frequencies predominantly between 6 and $12 \mathrm{~Hz}$. Shorter licking bouts tended to vary more in lick frequency than long bouts in both genotypes. The auto-correlograms shown in $\boldsymbol{B}$ are taken from the bouts that are indicated with larger, filled symbols. $\boldsymbol{D}$, Histograms of all interlick intervals within licking bouts showed similar distributions in WT and L7-PP2B mice, indicating that L7-PP2B mice had no motor deficits preventing them from licking rhythmically. The histograms were made with a bin size of $2 \mathrm{~ms}$, and the area under the plot was normalized to 100\%. Inset, Licking frequency \pm SEM averaged per mouse ( $n=9$ WT mice and 10 L7-PP2B mice; $p=0.773$ ). $E$, Whisker movements were quantified from high-speed video recordings. In each frame, the proximal parts of the whiskers were tracked with small line segments (colored lines in the right plot). Whisker angles were measured relative to the body axis. $\boldsymbol{F}$, Whisker motion during a whisking bout was tracked manually (top) and characterized using the motion detection algorithm (bottom; see Materials and Methods). It can be seen that the motion detection reliably captured the duration of the whisker movements. $\mathbf{G}$, The same fragment was subsequently analyzed using automated line detection and subsequent post-processing to detect movements of individual whiskers (see Materials and Methods); tracks with $>500$ data points are shown with randomly assigned colors, while shorter tracks are shown in gray. The orange trace refers to the same whisker that had been tracked manually (top trace in $\boldsymbol{F}$ ). $\boldsymbol{H}$, There is a clear negative correlation between the frequency and amplitude of a whisker bout: the higher the frequency, the smaller the movements. Linear regression lines of WT mice ( $n=47$ bouts from 10 mice) and L7-PP2B mice ( $n=46$ bouts from 11 mice) data were not significantly different from each other $(z=1.579 ; p=0.114) . I$, Neither the amplitude nor the frequency of whisker bouts was significantly different between WT and L7-PP2B mice $(p=0.378$ and $p=0.784$, respectively).

pedestal and habituated to the experimental setup for one $15 \mathrm{~min}$ session per day. During these sessions, water drops $(\sim 20 \mu \mathrm{l} /$ lick $)$ were triggered upon breaking the laser beam of the lick port. The mice did not receive extra water after the habituation sessions.

Upon completion of the habituation phase, the mice progressed to the association task to ensure that the L7-PP2B mutants and WT mice had similar levels of motor and sensory performance at the onset of localization training. In this respect, our protocol deviated from that in the study by O'Connor et al. (2010a), which was designed to describe correlates with cerebral cortical activity rather than to compare cerebellar pheno- types. During the association task, the mice learned to associate the rising of a bar $(\sim 1 \mathrm{~mm}$ diameter $)$ into their right whisker field with the availability of water at the lickport ("go trials"). The association trials started with a horizontal movement of the stimulation bar below the reach of their whiskers (lasting for $2 \mathrm{~s}$ ), followed by a vertical movement (lasting for $850 \mathrm{~ms}$ ) that placed the bar inside the whisker field ( $\sim 5 \mathrm{~mm}$ posterior and $10 \mathrm{~mm}$ lateral to the tip of the nose; Fig. 2A). Mice were able to touch the stimulation bar at some point during vertical rise of the stimulation bar. The exact moment of touch depended on the length and position of the whiskers at that time. To indicate the point in time in which the 

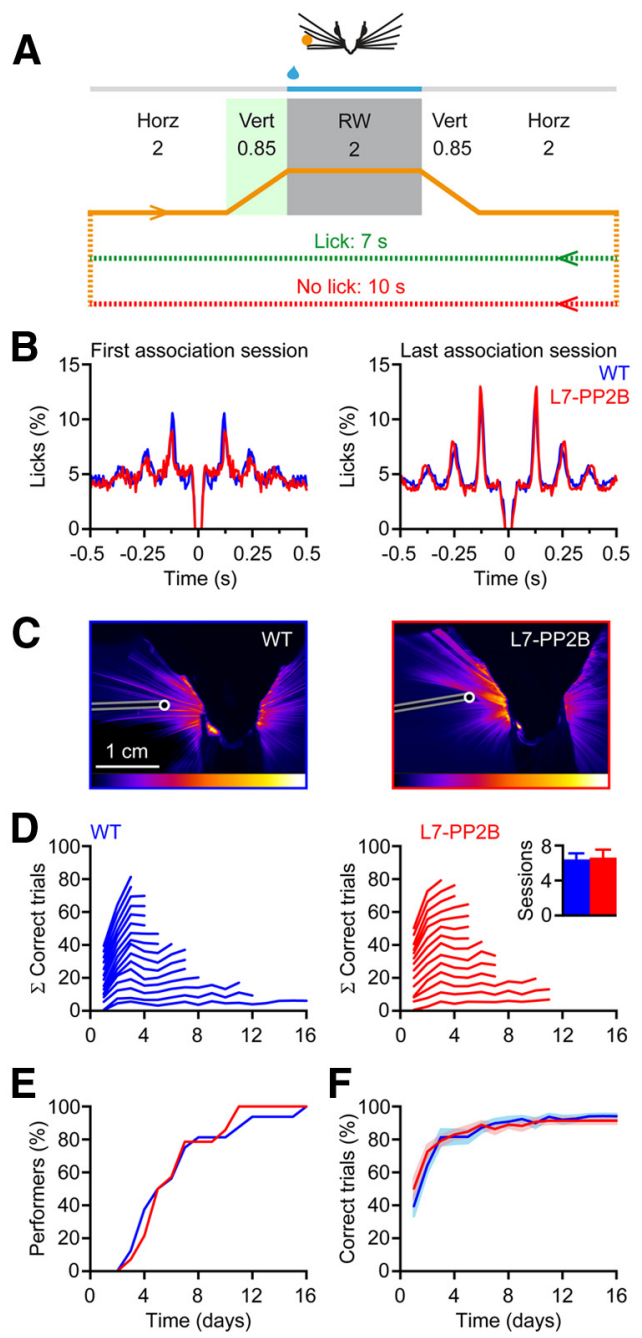

Figure 2. Mice learn to lick after feeling a stimulus bar in their whisker field. $A$, Learning paradigm. During the association task, mice were subjected only to go trials and learned to lick following whisker contact with a metal bar (orange dot) within a $2000 \mathrm{~ms}$ RW. Once the stimulation bar completed the horizontal movement from the (neutral) resting position to the go position, it moved vertically into the whisker field. Whisker contact with the stimulation bar became possible approximately half way through the time interval allotted for the vertical movement. To indicate this, we marked the time period of the vertical movement with a green shading. The RW started after the completion of the vertical movement and is indicated with a gray shading. Correct responses triggered a water reward; incorrect responses postponed the next trial. $\boldsymbol{B}$, Mice licked rhythmically during the RW of the association phase. Over the sessions, the mice increased their licking rhythmicity, as demonstrated by the increase of the amplitudes of the side peaks at approximately $125 \mathrm{~ms}$ [corresponding to a dominant lick frequency of $8 \mathrm{~Hz}$; compare with naive mice (during the first association session) in the left panel and trained mice (during the last association session) in the right panel]. The auto-correlograms were made with a bin size of $5 \mathrm{~ms}$ and were normalized to the center peak (which is not shown to improve (larity). C, SD projection plot showing a representative example of whisker movement during the RW. The color bar at the bottom indicates the amount of movement (black, no change; white, maximal change). It can be seen that both mice moved their whiskers actively during the RW and touched the stimulus bar. $\boldsymbol{D}$, Summed learning curves during the association phase (see Materials and Methods). The inset shows the average number of sessions required to reach the criterion. Error bars indicate SD. E, Cumulative histogram of the percentage of mice that reached criterion, showing that WT and L7-PP2B mice learned the association task at a similar rate. $\boldsymbol{F}$, The fraction of correct trials over the sessions. Dark lines show the averages, and the shaded areas cover the average \pm SEM.

whisker could touch the bar during vertical rise before onset of the RW, we indicated the period of upward movement with green shading in Figures 2, 3, and 4. Once the bar reached its highest position, the RW opened. A water droplet was triggered at the onset of the first lick in this window (Figs. 2, 3, 4, RW indicated with gray shading). The droplet remained at the lickport for the duration of the RW until all remaining water was sucked out of the lickport and the bar moved downward, returning to its starting position via the same route and at the same speed. When the animal did not respond to the stimulation during the RW during a trial, the next trial was postponed by an extra $3 \mathrm{~s}$, delaying the possibility of reinforcement at the next trial. Licking outside the RW did not have any positive or negative consequences, except for the absence of water outside the RW. Each mouse was trained for one session consisting of 100 trials per day. The association task was completed as soon as a mouse licked at least once within the RW in at least $80 \%$ of the trials for at least two consecutive sessions. To minimize visual cues, the entire task took place in complete darkness, except for some sessions in which we made a video of the whisker movements using infrared illumination; these videos were recorded with a full frame rate of $160 \mathrm{~Hz}$ using infrared lighting at $\lambda>900 \mathrm{~nm}$.

Localization learning. Following completion of the association task, mice continued with the object localization task, consisting of go trials and trials in which the mice were taught to refrain from licking ("no-go trials") on the following day. During a go trial, the stimulation bar moved horizontally in the caudal direction from the neutral position below the right whisker field to $\sim 5 \mathrm{~mm}$ posterior to the nose and then vertically into the whisker field, as described above. During a no-go trial, the stimulation bar moved horizontally from the neutral position into the rostral direction below the whisker field to $\sim 5 \mathrm{~mm}$ anterior to the nose, and then vertically into the whisker field. The no-go position was outside the whisker field at rest, but could be reached during active whisking. The actual distance between the go and the no-go position depended on the size of the head and varied between 8 and $11 \mathrm{~mm}$. A trial always began from and ended with the stimulation bar at rest in the neutral position, which was in the middle between the go and the no-go position, to ensure that the timing of any possible auditory cues during go and no-go trials was identical. During rest at the neutral position and during the horizontal movements, the stimulation bar was well below the reach of the whiskers. For both types of trials, the RW started as soon as the vertical movement of the bar was completed, but only during the go trials were the mice were rewarded with a drop of water when they licked the lickport within the RW. The total duration of a trial was $\sim 6.2-7.7 \mathrm{~s}$, depending on the duration of the RW, followed by an intertrial interval of $7 \mathrm{~s}$ in correct trials. An incorrect response (not licking) during a go trial resulted in an extra intertrial interval of $3 \mathrm{~s}$, whereas an erroneous response (licking) during a no-go trial resulted in an extra intertrial interval of $8 \mathrm{~s}$ (Fig. 3A). Each (daily) session consisted of 100 pseudo-randomized trials (50\% go trials and $50 \%$ no-go trials) or until the mouse discontinued licking, which was defined as not showing any responses for 10 consecutive trials. For each session, we calculated the percentage of correct trials, taking both the go and the no-go sessions into account. Once the mice performed at $\geq 80 \%$ correct during two consecutive sessions of the localization task with an RW of $2000 \mathrm{~ms}$, the RW was decreased to $500 \mathrm{~ms}$ (via an intermediate step using an RW of 1000 ms; Figs. 3, 4, 5). Mice that did not learn the $2000 \mathrm{~ms}$ localization task within 35 sessions were considered nonperformers, and they were not tested any further. For control, we cut all whiskers in 10 mice (under isoflurane anesthesia) following completion of the $500 \mathrm{~ms}$ localization task, and we tested their performance again on the next day.

Constructing learning trajectories. For each session, we plotted the average hit rate and average false alarm rate per group of all mice (Fig. 6). To this end, we calculated the hit rate [i.e., the fraction of correct responses (licks) during the go trials relative to all go trials] and the false alarm rate [i.e., the fraction of incorrect responses (licks) during the no-go trials relative to all no-go trials] for each mouse and for each session. Linear regression lines were fitted to the group averages, and the deviation from the linear regression was calculated as the least-squares difference (SigmaPlot, Systat Software). The sensitivity index $\left(d^{\prime}\right)$ was calculated using the $z$-transformations of the hit rate and the false alarm rates $\left[d^{\prime}=z\right.$ (hit rate) $-z$ (false alarm rate)], assuming a Gaussian distribution. The $80 \%$ correct level corresponded to a $d^{\prime}$ score of $\sim 1.7$ (Huber et al., 2012).

Electrophysiology. Electrophysiological recordings were performed in awake mice as described previously (Bosman et al., 2010). Briefly, mice first received a craniotomy of the occipital bone under isoflurane anes- 
A

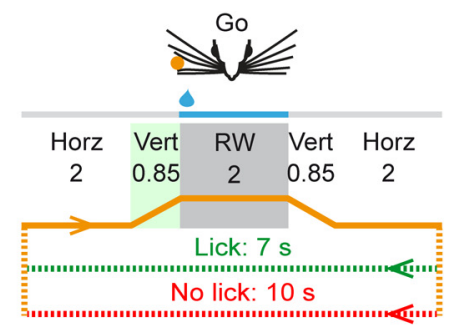

$B_{15}$

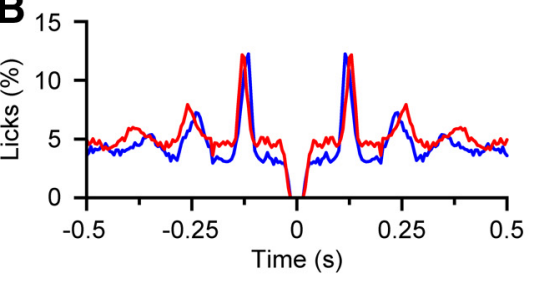

C

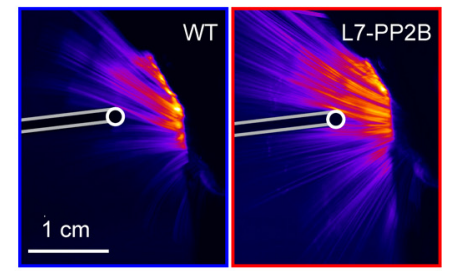

D $\quad$ WT

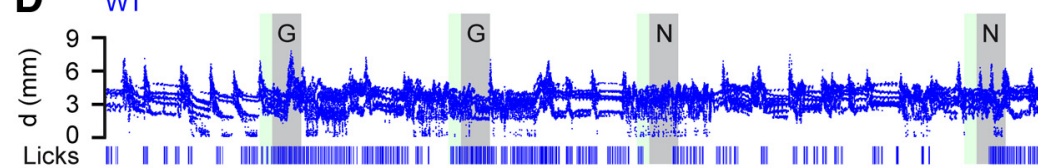

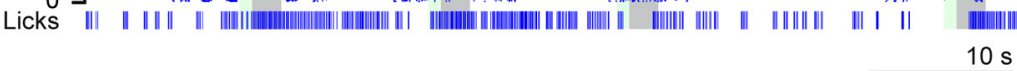

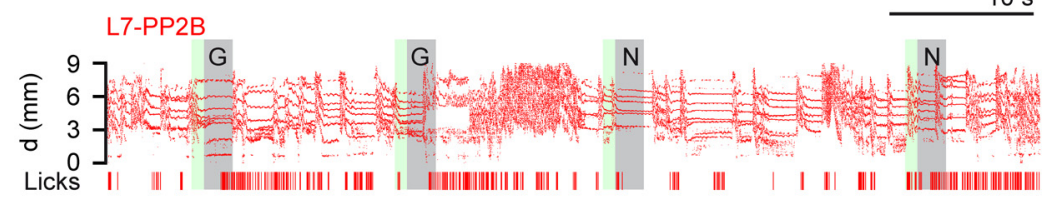

E

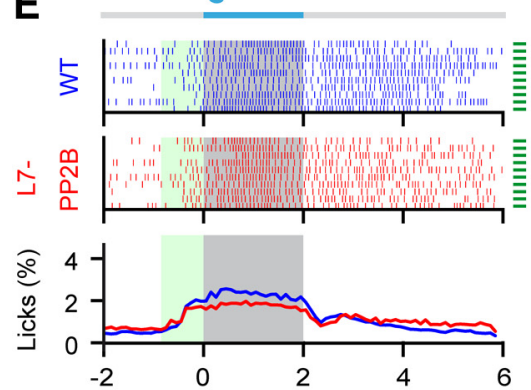

First

F

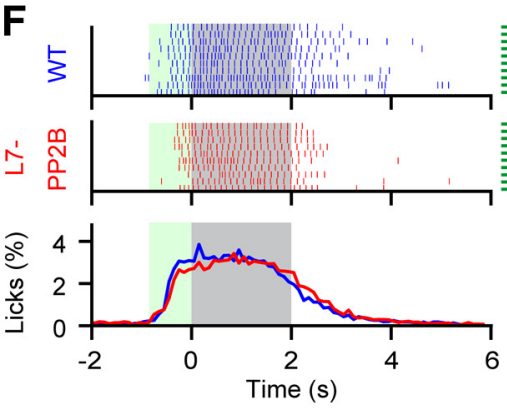

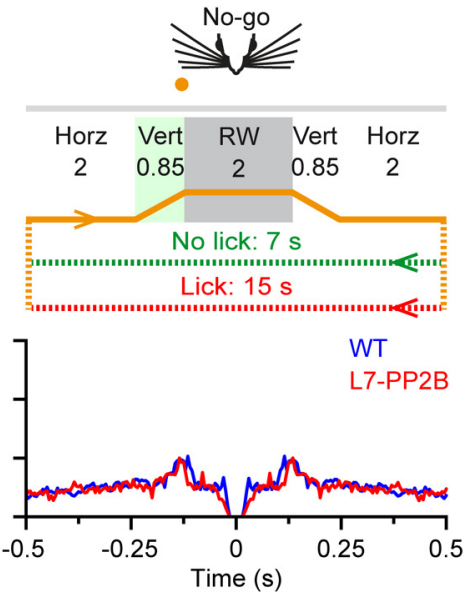

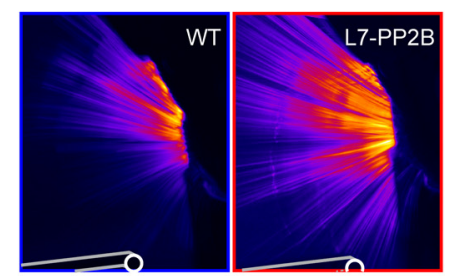

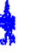

\section{s.}


A
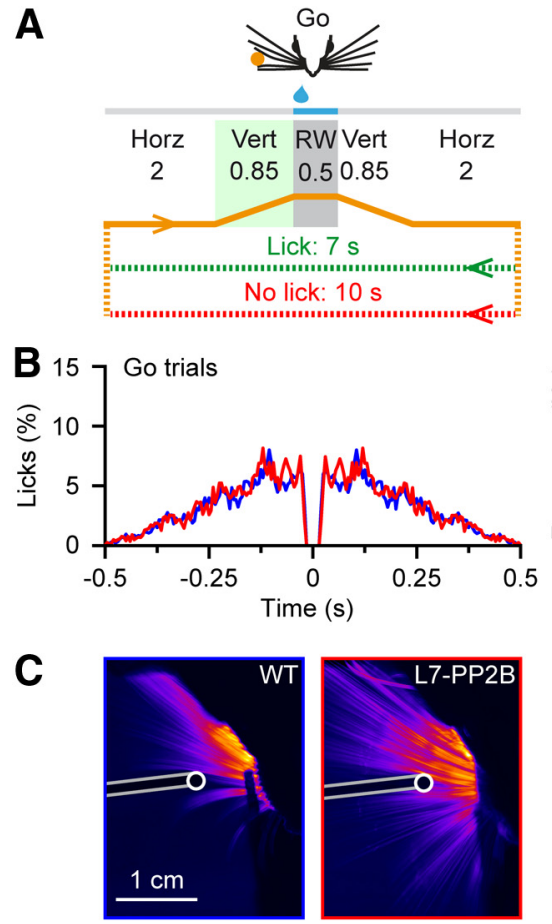

D WT
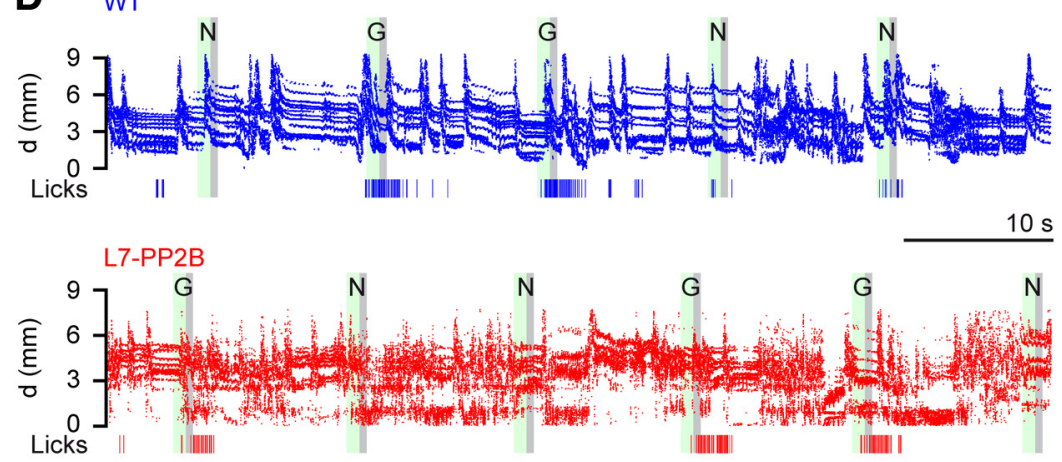

E

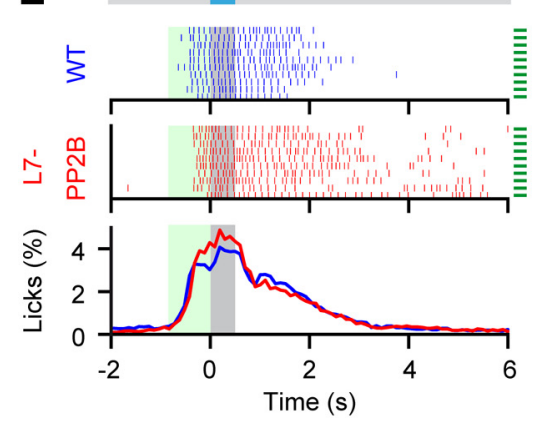

Last
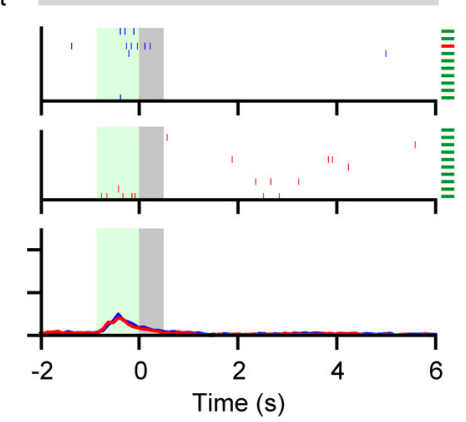

Figure 4. Motor behavior during the object localization task with an RW of $500 \mathrm{~ms}$. A, Learning paradigm. Once the stimulation bar completed the horizontal movement from the (neutral) resting position to the go or the no-go position, it moved vertically into (go) or just in front of (no-go) the whisker field. Whisker contact with the stimulation bar became possible approximately around half way during the time interval allotted for the vertical movement. To indicate this, we marked the time period of the vertical movement with a green shading. The RW started after the completion of the vertical movement and is indicated with gray shading. Licks during the RW of go trials triggered a water reward; incorrect responses postponed the next trial. $\boldsymbol{B}$, Mice licked rhythmically during the RW of go trials of the last $500 \mathrm{~ms}$ object localization session. At this stage, the mice performed so well that licking during no-go trials was really sparse and that there were not enough licks during the RW of no-go trials to permit quantitative analysis. $C$ SD projection plot showing a representative example of whisker movement during the RW. It can be seen that both mice moved their whiskers actively during the RW and touched the stimulus bar, both in the go and in the no-go trials. $\boldsymbol{D}$, Example traces of whisker movements during the last session of the $500 \mathrm{~ms}$ object localization task, illustrating that mice of both genotypes whisk often during the task. Plotted are the rostrocaudal positions of the center whiskers at $\sim 3 \mathrm{~mm}$ from the snout. Intertria whisking occurs less often in trained mice than in naive mice (compare Fig. 3D). Licks are indicated in the bottom rows. and the complete time of the vertical descent of the bar following the RW. The intertrial interval was defined as the period between the end of the (second) horizontal movement of one trial and the start of the (first) horizontal movement of the next trial. The local variation in simple spike firing (CV2) was calculated as $\mathrm{CV} 2=2\left|\mathrm{ISI}_{n+1}-\mathrm{ISI}_{n}\right| /\left(\mathrm{ISI}_{n+1}+\mathrm{ISI}_{n}\right)$, where ISI is the interspike interval (Shin et al., 2007).

Data analysis. Summed learning curves were made for both the association stage and the object localization task. First, we calculated for each mouse and each session the percentage of correct responses, and divided that percentage by the number of mice in that group. For example, if the group size was 14 mice, each individual mouse had a normalized success rate between $0 \%$ and $100 \% / 14=7.14 \%$. Next, we sorted the mice per group based on the number of sessions they required to reach criterion. The lowest line represents the normalized learning curve for the mouse that needed the most sessions. The second line from below is the sum of the normalized success rate of the first mouse plus that of the second mouse and so on. Each additional line is the sum of the normalized success rates of that mouse and of the mice represented by the lines below that line. As a consequence, the top line represents the group average. Unless stated otherwise, data are represented as the mean \pm SEM, and statistical testing was performed using Student's $t$ test. For unrelated tests, we used a $5 \%$ level of significance. For repeated tests, the level of significance was corrected using Bonferroni's correction $\left(\alpha_{\text {corr }}=\alpha / n\right.$ with $\alpha=0.05$ and $n=$ number of tests). Where Bonferroni's correction was applied, $\alpha_{\text {corr }}$ is mentioned in the text.

\section{Results}

\section{Licking in freely moving mice is} comparable across genotypes

Since we are using licks as the readout parameter of learning capabilities during the object localization task, putative deficits in motor aspects of licking could in principle create a bias in the learning performance. Therefore, we first studied the licking behavior of WT and L7-PP2B mice in their home cages. Both WT $(n=9)$ and L7-PP2B mice $(n=10)$ licked during

Go trials are indicated with a "G," no-go trials with an "N." A longer intertrial interval indicates an incorrect response. $\boldsymbol{E}$, Raster plots of lick times showing the last $10 \mathrm{go}$ (left) and no-go trials (right) of representative experiments during the first session of the 500 ms object localization task. The two top panels show raster plots for a single individual per genotype. The lines at the right border of the plot indicate whether the trial was performed correctly (green) or incorrectly (red). The bottom panel shows the histograms of the relative timing of the licks over all trials averaged for all performers. The green area $(850 \mathrm{~ms}$ ) refers to the interval during which the stimulation bar moved vertically, either into (go trials) or in front of (no-go trials) the resting position of the whisker field. The gray area indicates the response window (500 ms). 

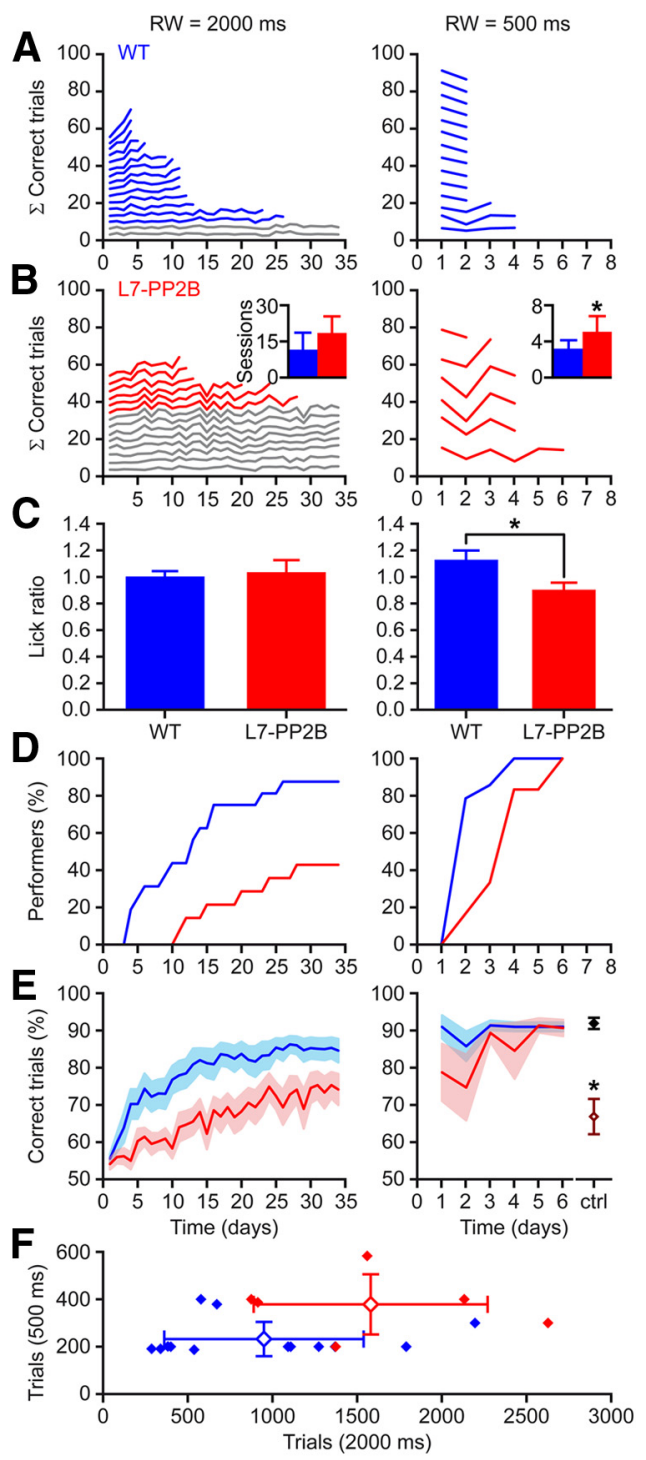

Figure 5. The absence of PP2B in cerebellar Purkinje cells impairs learning of a whiskerbased object localization task. A, Summed learning curves of WT mice during the $2000 \mathrm{~ms}$ (left) and the $500 \mathrm{~ms}$ (right) object localization task across consecutive sessions ( $x$-axis). The number of trials per session was normalized to $100 \%$ (for details, see Materials and Methods). Upon reaching a success rate of $\geq 80 \%$ during two consecutive sessions, mice continued to the next phase. Performers and nonperformers are indicated in blue and gray, respectively. $\boldsymbol{B}$, Same as $\boldsymbol{A}$ for L7-PP2B mice (performers are indicated in red). Insets, Averaged number of sessions \pm SD that performers needed to complete the entire object localization task; ${ }^{*} p<0.017$ ( $t$ test). $C$, The fine timing of the lick responses at the end of the $100 \mathrm{~ms}$ period preceding the $\mathrm{RW}$ and at the first $100 \mathrm{~ms}$ period of the RW suggests a cerebellar role in the timing of the decision process to lick. We compared the number of licks during the first $100 \mathrm{~ms}$ of the RW and the $100 \mathrm{~ms}$ before the start of the RW, and thus the ratio of licks just after the availability of water and the licks just before the availability of water. This ratio equaled 1 during the last session of the $2000 \mathrm{~ms}$ object localization task (left), but was increased in trained WT mice (but not in L7-PP2B mice) during the last 500 ms object localization task (right); ${ }^{*} p<0.02$. D. Cumulative histograms of the percentage of mice that reached criterion showing that more WT mice were able to learn the object localization task than L7-PP2B and that WT performers were faster than L7-PP2B performers. $\boldsymbol{E}$, The fraction of correct trials over the sessions. Dark lines show the averages, and the shaded areas cover the average \pm SEM. For a control, we clipped the whiskers of 10 mice (8WT mice and 2 L7-PP2B mice) following successful completion of the $500 \mathrm{~ms}$ object localization task. Their performance level during the subsequent session (dark red open symbol) was comparable to that of naive mice and was much lower than that during the last session with intact whiskers (black closed symbol); ${ }^{*} p<0.001$ (paired $t$ test). $\boldsymbol{F}$, The average numbers of trials the L7-PP2B mice needed to learn the 500 and $2000 \mathrm{~ms}$ object localization tasks were significantly greater than those in WT mice $(p<0.05)$. multiple periods. Such licking periods often consisted of a few bouts of uninterrupted licking, each of which consisted of a series of rhythmic licks (Fig. 1A,B). Neither the licking frequency $(9.15 \pm 0.13 \mathrm{~Hz}$ for WT vs $9.08 \pm 0.18 \mathrm{~Hz}$ for L7-PP2B mice) nor the number of licks per bout $(5.7 \pm 0.6$ and $5.4 \pm 1.1$ licks $)$ differed significantly among genotypes $(p=0.773$ and $p=0.841$, respectively; Fig. $1 C, D$ ). In addition, the distributions of interlick intervals within bouts were similar between WT and L7-PP2B mice $(p=0.693$, Kolmogorov-Smirnov test; Fig. $1 D)$. These data indicate that the baseline licking performance of freely moving L7-PP2B mice is intact.

\section{Free whisking in head-restrained mice}

Putative abnormal whisker use could be a cause for deficits in the results of our whisker-based object localization task. Therefore, we quantified the spontaneous whisker movements of 10 untrained WT mice and 11 L7-PP2B littermates during recording sessions in which no whisker stimulation took place (Fig. 1E). To facilitate the automated detection of whisker movements, we first quantified whisker motion (see Materials and Methods). The whisker motion algorithm reliably identified periods with whisker movements, as verified by manual tracking (see Materials and Methods; Fig. $1 F$ ). The video fragments containing whisker movement were further analyzed quantitatively using BWTT (Perkon et al., 2011) and post-processed to track traces of individual whiskers over time (Fig. 1G). We confirmed the accuracy of automatically traced tracks with manually traced tracks [Fig. $1 F$, orange trace (which is derived from the same whisker as the orange/bottom trace in Fig. $1 G$, but was made from a more distal location, accounting for the sharper peaks)]. We found that all mice showed repetitive periods of whisking. We quantified the movements of individual whiskers during bouts of rhythmic whisking. Within such bouts, neither the amplitude (WT mice: $29.5 \pm 2.5^{\circ}$; L7-PP2B mice: $\left.26.9 \pm 2.4^{\circ} ; p=0.378\right)$ nor the frequency (WT mice: $17.5 \pm 1.6 \mathrm{~Hz}$; L7-PP2B mice: $18.1 \pm 1.5$ $\mathrm{Hz} ; p=0.784)$ differed significantly between the two groups of mice (Fig. $1 G-I$ ). There was a clear inverse correlation between the amplitude and the frequency of a whisker bout (WT mice: $r=$ 0.503; $p<0.001$; L7-PP2B mice: $r=0.606$; $p<0.001$; linear regression; Fig. $1 H$ ). The regression lines of the WT and the L7-PP2B mice were not significantly different from each other $(z=1.579 ; p=0.114)$. We conclude that WT and L7-PP2B mice are similar in their range and frequency of free whisking.

\section{General motor performance during the association stage}

Since the frequency of licking can depend on the ease of access to water (Weijnen, 1998), we also compared the licking behavior in head-restrained mice during the association task when water was available during the $2000 \mathrm{~ms}$ RW. Overall, the average number of licks per minute-as calculated over the whole first association session-was comparable between head-restrained WT $(n=16)$ and L7-PP2B $(n=14)$ mice (WT mice: $96 \pm 18$ licks/min; L7PP2B mice: $120 \pm 24$ licks/min; $p=0.535$; data not shown). Most mice [14 of $16(87.5 \%)$ WT mice and 14 of 14 (100\%) L7-PP2B mice; $p=0.485$, Fisher's exact test] licked rhythmically during the RW of the first association session. WT mice had a slightly different licking frequency, but the difference with L7-PP2B mice was not significant $(f=8.3 \pm 0.1 \mathrm{~Hz}$ and $7.9 \pm 0.1 \mathrm{~Hz}$, respectively; $p=0.06$ ). The strength of the rhythmicity was similar $(13.0 \pm 0.8 \%$ and $11.8 \pm 0.7 \%$, respectively; $p=0.306$; Fig. $2 B)$. As the association training proceeded, rhythmic licking during the RW increased; at the end, the strength of the rhythmicity was $15.1 \pm 1.0 \%$ and $14.3 \pm 0.9 \%$, respectively, for WT and L7-PP2B 
A
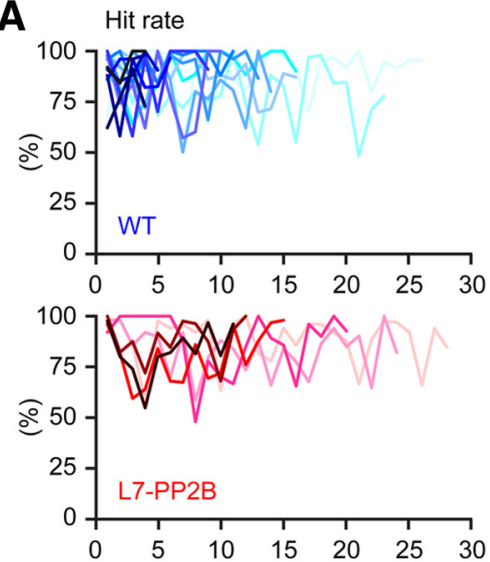

B

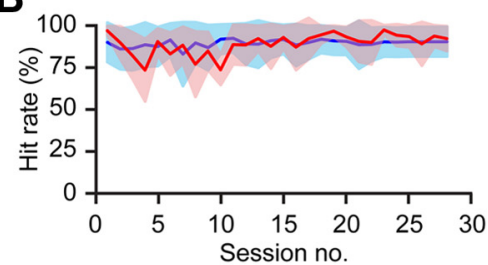

C

C -2000 ms object localization task

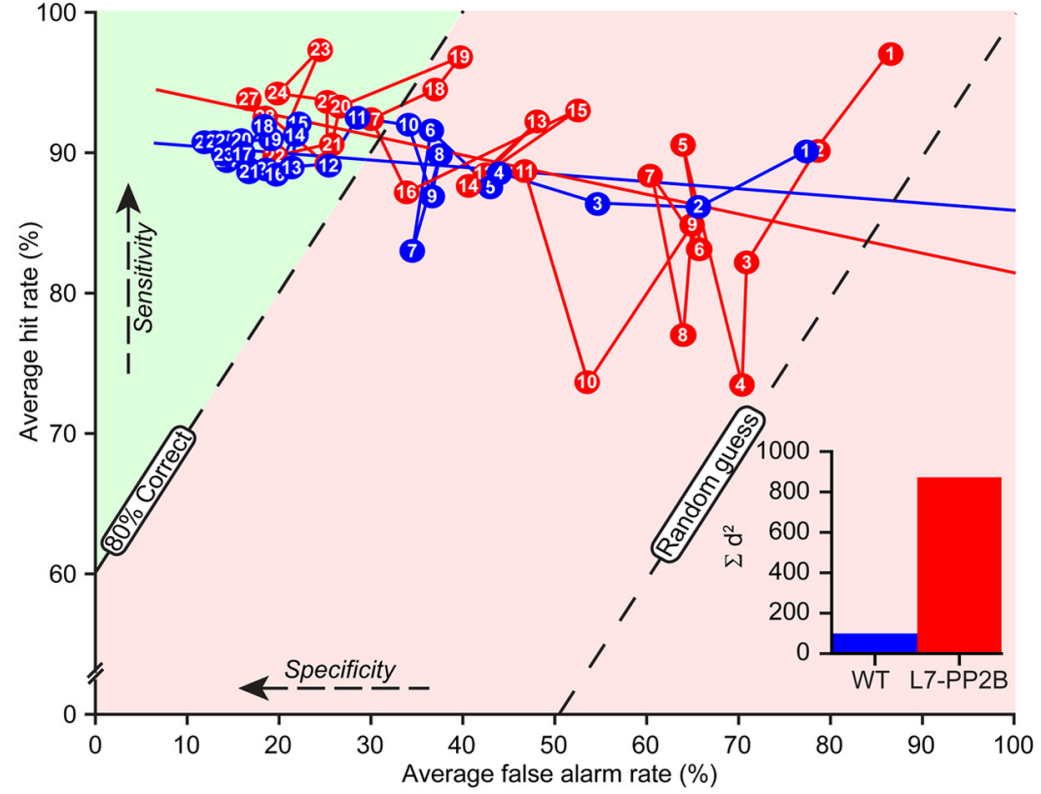

D -2000 ms object localization task

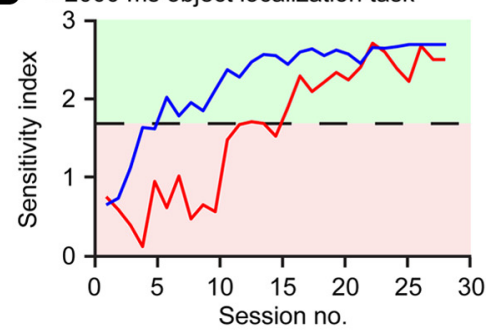

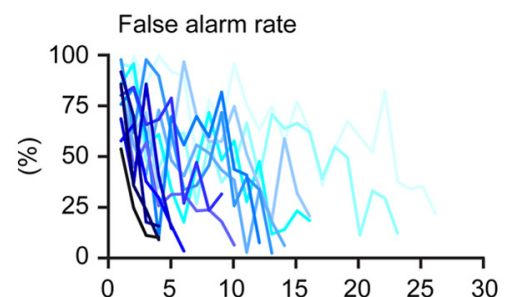
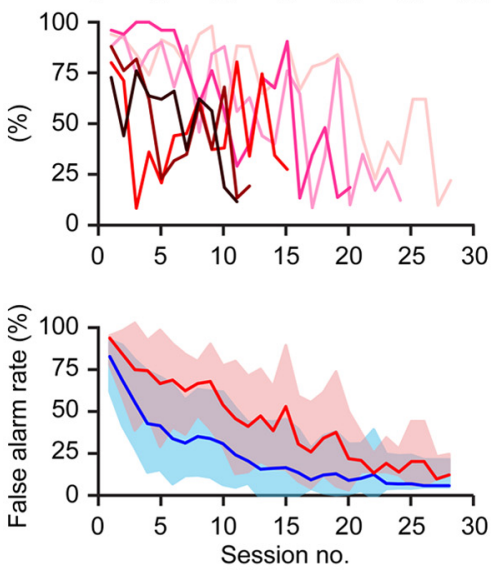

E- 500 ms object localization task

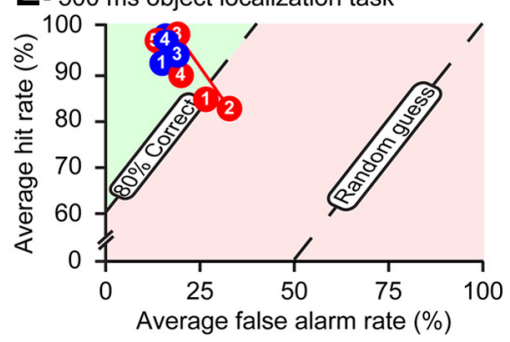

Figure 6. WT mice have more efficient learning trajectories than L7-PP2B mice. $\boldsymbol{A}$, The hit rates (licking during the RW of go trials; left) and the false alarm rates (licking during the RW of no-go trials; right) of all WT (top) and L7-PP2B (bottom) performers over the sessions of the $2000 \mathrm{~ms}$ object localization task. $\boldsymbol{B}$, Averaged hit (left) and false alarm (right) rates of all performers. Dark lines indicate the average, and the shaded area the average \pm SD. C, Average false alarm rates versus average hit rates in ROC space during the $2000 \mathrm{~ms}$ object localization task. Perfect classification of both the go trials and the no-go trials would be $0 \%$ false alarms and $100 \%$ hits. Successful trials ( $\geq 80 \%$ correct) can be found in the green area. Plotted are the averages of all WT (blue) and L7-PP2B (red) performers for 28 sessions (the session number is indicated on each symbol), which was the maximum number of sessions required to master the 2000 ms object localization task. Linear regression lines are indicated. Note that the WT

mice $(p=0.576)$. The frequency remained at $\sim 8 \mathrm{~Hz}$ for both groups (7.9 \pm 0.1 and $7.8 \pm 0.1 \mathrm{~Hz}$, respectively; $p=$ $0.624)$. Moreover, video analyses of the whisker movements showed that WT and L7-PP2B mice were both actively whisking during the association trials. Figure $2 C$ shows an example of whisker movements in a video of a WT and a L7-PP2B mouse during the first session of the association task. Both mice whisked actively and contacted the stimulation bar during the RW of the association task. Thus, as in naive mice, both WT and L7-PP2B mice had similar lick responses and active whisker exploration behavior while being head restrained during the RWs of the association task.

\section{Association learning}

Next, we analyzed the performance of the mice during the association training. We identified a trial as correct when a mouse licked at least once within the RW, independent from its activity outside the RW. On average, both groups had similar percentages of correct trials during the first session when the rod was elevated inside the whisker field (WT mice: $39.4 \pm$ 24.6\%; L7-PP2B mice: $50.1 \pm 24.2 \%$, mean $\pm \mathrm{SD} ; p=0.241)$. In addition, both genotypes learned equally well during the association task (last session: WT mice, $93.8 \pm 5.4 \%$; L7-PP2B, $91.4 \pm 7.1 \%$, mean $\pm \mathrm{SD} ; p=0.238)$. WT and L7-PP2B mice required a similar number of sessions to reach criterion $(6.6 \pm 3.6$ and $6.4 \pm 2.6$ sessions, respectively, mean \pm SD; $p=0.865$; Fig. $2 D$; see also Table 1 ). The rate at which the mice mastered the task was very similar for WT and L7-PP2B mice ( $p=0.458$, paired $t$ test; Fig. $2 E$ ). Also, the learning curve, represented as the percentage of correct trials per session, was highly comparable for both types of mice $(p=0.963$, repeated-measures ANOVA; Fig. 2F). Thus, all mice-regardless of their genotype-learned to lick

$\leftarrow$

mice decrease the number of false alarms from the beginning on, while the L7-PP2B mice first generally reduce the licking responses, regardless of the trial type. The linear regression lines of WT and L7-PP2B mice are not significantly different $(z=1.498 ; p=0.134)$. Inset, Summed least-squares differences between the first 28 sessions and the linear regression lines for WT and L7-PP2B performers during the $2000 \mathrm{~ms} \mathrm{ob}$ ject localization task. $\boldsymbol{D}$, The $d^{\prime}$ of all animals $(0=$ chance performance; $1.68=80 \%$ correct trials). $\boldsymbol{E}$, The same plotas $\boldsymbol{C}$, but for the $500 \mathrm{~ms}$ object localization task. Note that the WT mice are in the green area from the start on, while the L7-PP2B mice initially show a decreased performance relative to the previous phases of the object localization tasks. 
Table 1. Number of trials for each phase of the learning paradigm

\begin{tabular}{lllr}
\hline & & $2000 \mathrm{~ms}$ RW & \\
\cline { 3 - 4 } & Association & Nonperformers & Performers \\
\hline WT mice & $511 \pm 303(n=16)$ & $950 \pm 589(n=14)$ \\
L7-PP2B mice & $535 \pm 253(n=14)$ & $2918 \pm 532(n=2)$ & $232 \pm 72(n=14)$ \\
$\quad$ P value & 0.810 & $3041 \pm 283(n=8)$ & $1581 \pm 690(n=6)$ \\
\hline
\end{tabular}

Values are given as the mean \pm SD. Each session consisted of up to 100 trials. On average, WT and L7-PP2B mice required a similar number of trials to master the association phase. Nonperformers (at the 2000 ms RW test) also received comparable numbers of trials. However, those L7-PP2B mice that were able to learn the object localization task needed more trials than their WT littermates. This was especially true for the 500 ms RW test.

*Significance was tested with two-way ANOVA (genotype: $p<0.001$ ) and subsequent $t$ tests.

during the RW of the association test at a similar pace.

\section{General motor performance during localization training}

Following completion of the association stage, during which mice only received go trials, they were subjected to the localization learning task, wherein they received both go and no-go trials. During the go trials, the pole was positioned inside the whisker field (as in the association stage), whereas during the no-go trials the pole was raised just in front of their baseline whisker field so they could only detect the rod by means of active forward exploration (Fig. $3 A$ ). In contrast to the go trials, when the mice were encouraged to lick, they had to withhold their licking during no-go trials to prevent a long delay for the next trial, postponing potential reinforcement.

First, we subjected the animals to trials with an RW of 2000 $\mathrm{ms}$, and we analyzed the licking pattern during the RWs of the first localization session. Licking was more rhythmic during the RW of go trials, when the mice received water, than during that of no-go trials, when the mice did not receive water (Fig. $3 B$ ). During go trials, the lick rhythm was again $\sim 8 \mathrm{~Hz}$ for both genotypes (WT mice: $8.2 \pm 0.1 \mathrm{~Hz}$; L7-PP2B mice: $7.9 \pm 0.1 \mathrm{~Hz}$; $p=0.085$ ), and both genotypes had a similar strength of rhythmic licking $(15.6 \pm 1.0 \%$ and $14.4 \pm 0.6 \%$, respectively; $p=0.304, t$ test $)$. During no-go trials, the lick rhythm was $8.1 \pm 0.2 \mathrm{~Hz}$ for WT mice and $7.4 \pm 0.2 \mathrm{~Hz}$ for mutants $(p=0.072)$, and the amplitudes were $7.9 \pm 1.0 \%$ and $7.4 \pm 0.9 \%$, respectively $(p=0.710)$. Likewise, when we analyzed the whisking behavior during the localization task (from 5 WT and 5 L7-PP2B mice), we found active whisking during both go and no-go trials, regardless of the genotype of the mouse (Fig. $3 C, D$ ). For this reason, we concluded that, at least initially, the mice were localizing both stimulus positions rather than simply detecting the stimulus during the go trials. Note that the mice could already sense the stimulation bar before it reached the top position. The moment of contact could vary per trial and depended on the actual position of the whiskers. Since mice could contact the stimulation bar as it moved upward into the whisker field, we indicated this period with green shading in Figures 2, 3, and 4. On average, there were 13.3 \pm 5.9 times as many licks during the "green period" of go trials than during that of no-go trials in expert mice $(p<0.001$, paired $t$ test; Fig. $3 F)$. The ratio was higher in WT mice $(17.2 \pm 7.8)$ than in L7-PP2B mice $(4.3 \pm 1.1)$, but this difference was not significant $(p=$ $0.147)$. Together, this indicates that although there were licks before the start of the RW, these early licks were mainly related to go trials, indicating the presence of whisker contact just before the start of the RW. We found a tendency that WT mice were better able to categorize trials in an early phase of the trial than L7-PP2B mice, since WT mice especially showed many more licks during the early onset of go trials than during that of no-go trials.

The mice that performed well during the $2000 \mathrm{~ms}$ object localization task were ultimately tested with the same test with an
RW of $500 \mathrm{~ms}$ (Fig. 4A). During the $500 \mathrm{~ms}$ RW of the go trials, mice again licked rhythmically at $\sim 8 \mathrm{~Hz}$ (frequency: WT mice, $8.8 \pm 0.4 \mathrm{~Hz}$; L7-PP2B mice, $8.5 \pm 0.3 \mathrm{~Hz} ; p=0.514$; amplitude: WT mice, $10.3 \pm 0.8 \%$; L7-PP2B mice, $9.2 \pm 1.0 \% ; p=0.385$ ). During this task, high-frequency tongue movements were relatively abundant in both WT and L7-PP2B mice, leading to a similar shape of the auto-correlograms ( $p=0.795$, KolmogorovSmirnov test; Fig. $4 B$ ). This high-frequency licking was probably due to the shorter time period of the presence of water at the lickport (500 ms instead of $2 \mathrm{~s}$ ). Licking during the RW of no-go trials was very sparse in both trained WT and mutant mice (Fig. $4 E)$, precluding a meaningful quantification of lick rhythmicity during the no-go trials. During the last session of the $500 \mathrm{~ms}$ object localization task, both WT and L7-PP2B mice whisked actively during both go and no-go trials (Fig. 4C), but, compared with naive mice, both genotypes whisked less during intertrial intervals (compare Figs. 3D, 4D).

\section{More WT than L7-PP2B mice learned the localization task}

Contrary to the association phase, which could be mastered by all mice, the object localization task with a 2000 ms RW was not learned by all mice. Of the $16 \mathrm{WT}$ mice, 14 reached a success rate of $>80 \%$ correct trials during two consecutive sessions within 35 daily sessions. Significantly fewer L7-PP2B mice were able to learn this task: only 6 of 14 mice succeeded in obtaining the same criteria $(87.5 \%$ vs $42.9 \%$; $p=0.019$, Fisher's exact test; Fig. $5 A, B$, left panels). The mice that did not manage to learn the object localization task with an RW of 2000 ms were considered to be nonperformers and were not tested any further. Mice that did obtain the necessary criteria were considered performers and were moved to the short RW-phase paradigm.

\section{WT performers learned the localization task faster than L7-PP2B performers}

WT performers were faster learners than L7-PP2B mice. For example, the fastest WT mouse took four sessions to master the 2000 ms localization task, whereas the fastest L7-PP2B mouse needed 11 sessions. The complete task including both the 2000 and $500 \mathrm{~ms}$ localization tasks was learned significantly faster by WT mice than by L7-PP2B performers [genotype: WT mice $(n=$ $14), 17.4 \pm 8.7$ sessions; L7-PP2B mice $(n=6), 24.8 \pm 7.7$ sessions, mean $\pm \mathrm{SD} ; F_{(1,54)}=4.395 ; p=0.041$, two-way ANOVA; Fig. $5 A, B$; Table 1 , number of trials). With regard to the $2000 \mathrm{~ms}$ object localization task only, it took the L7-PP2B mice longer to learn the task than the WT mice, but this difference did not reach statistical significance [WT mice: $11.6 \pm 7.0$ sessions; L7-PP2B mice: $18.5 \pm 6.9$ sessions, mean $\pm \mathrm{SD} ; p=0.090$ (not significant: $\alpha_{\text {corr }}=0.017$; see Materials and Methods), Mann-Whitney test; Fig. $5 A, B, D]$. The reduced learning efficiency of the L7-PP2B mice was also reflected in the slower increase of correct responses during the $2000 \mathrm{~ms}$ task (genotype: $F_{(1,27)}=5.098 ; p=0.032$, repeated-measures ANOVA; Fig. 5E). 


\section{WT mice learned to fine-tune the timing of their lick responses better than $\mathrm{L} 7-\mathrm{PP} 2 \mathrm{~B}$ mice}

When we reduced the RW from 2000 to $500 \mathrm{~ms}$, the L7-PP2B mice required on average significantly more sessions than their WT littermates to reach criterion (WT mice: $2.4 \pm 0.7$ sessions; L7-PP2B: $3.8 \pm 1.3$ sessions; $p=0.010$ [significant: $\alpha_{\text {corr }}=0.017$, Mann-Whitney test); Fig. $5 A$, $B$; Table 1 , number of trials]. Thus, while the L7-PP2B mice in general had more difficulties learning the object localization task, the difference with WT mice was especially clear when fast response timing was required.

Further evidence for this claim was indicated by the differences in precise timing of the licks between WT and L7-PP2B mice. We compared the number of licks just before the RW to the number of licks just after the start of the RW in which the water reward became available. The ratio of the licks between $100 \mathrm{~ms}$ after and $100 \mathrm{~ms}$ before the start of the RW was not significantly different between WT and L7-PP2B mice at the end of the training with the $2000 \mathrm{~ms}$ RW (WT mice: $1.01 \pm 0.04$; L7-PP2B mice: $1.04 \pm 0.09 ; p=0.758$ ). This indicates that the mice did not time their licks very precisely around the onset of the RW. However, at the end of the training with the $500 \mathrm{~ms}$ RW, the WT mice showed a clear increase in licking just at the onset of the RW. In contrast, the L7-PP2B mice did not (WT mice: $1.13 \pm 0.07$; L7-PP2B: $0.91 \pm 0.05 ; p=0.019$; Fig. $5 C)$. These data point at reduced sensorimotor timing abilities in L7-PP2B mice that become apparent only under strict timing restraints. Importantly, whisker clipping following training with an RW of 500 ms significantly affected the performance during the object localization task (from $91.9 \pm 1.51 \%$ to $66.8 \pm 4.8 \% ; n=10$ mice; $p<0.001$, paired $t$ test; Fig. $5 E$, right), confirming that mice predominantly used their whiskers to detect the stimulus bar and respond accordingly. However, as the performance level after whisker clipping did not return completely to the $50 \%$ chance level (go and no-go trials occurred equally often), we cannot exclude the possibility that some mice also partially used other sensory cues like sound and vibration to facilitate the whisker-based localization task.

Since not all sessions had an equal number of trials, we also compared the number of trials per individual required for the 2000 and $500 \mathrm{~ms}$ tasks. This confirmed that WT mice were in general faster in learning than L7-PP2B mice (Fig. 5F; Table 1). Moreover, together with the more accurate timing of the licks in WT mice (Fig. 5C), these data indicated that the differences among WT and L7-PP2B mice are more prominent with shorter RWs.

WT mice show a better learning trajectory than L7-PP2B mice Since we found that the WT and L7-PP2B mice differed in their learning skills during the object localization task, we further investigated the relative contributions of their licks during the go trials and the withholding of their licking during the no-go trials to the overall learning process. First, we plotted for all performers the individual learning curves of the hit rates (i.e., the percentages of go trials during which the mice licked during the RW) and the false alarm rates (i.e., the percentages of no-go trials during which the mice licked during the RW; Fig. $6 A, B)$. It can be seen that mice started the object localization training with both high hit rates and false alarm rates, and gradually learned to refrain from licking during the no-go trials. This behavior was further analyzed by plotting the "false alarm" rates vs the "hit" rates for each session of the object localization task. Separate plots of the learning trajectories were constructed in receiver operating characteristic (ROC) space (Fig. 6C). As mentioned before, the mice were trained during the preceding association phase to lick during all trials. Consequently, during the first object localization session (with a $2000 \mathrm{~ms}$ RW) they licked very often regardless of the trial type. As a result, they performed at close to the guess rate.

During the subsequent sessions, the WT performers markedly and consistently increased accuracy, moving almost along a straight line toward our defined criteria (Fig. 6C, green area). They continued to lick during the go trials, but decreased their licking during no-go trials. Thus, they maintained a high level of sensitivity to go trials, but specifically reduced their response to no-go trials. The WT mouse with the fastest learning capability reached criterion after four sessions, whereas the fastest L7-PP2B mouse reached criterion only after 11 sessions (Fig. $5 A, B$ ). In contrast to WT mice, the L7-PP2B mice reduced their licking during the first four sessions in a random fashion: they stayed close to the guess rate. The difference between the WT and L7PP2B mice during these first four sessions was striking. The WT mice kept licking at the same rate during the go trials, but reduced their licking during the no-go trials. In contrast, the L7-PP2B mice initially did not discriminate between go and no-go trials.

In the subsequent sessions, the six L7-PP2B performers also increased their successful licks, but their learning trajectories remained noisier than those of the WT performers. This difference in learning trajectories was particularly evident when comparing the deviations from the linear regression between the WT and L7-PP2B performers (Fig. $6 C$, inset). The linear regression lines themselves were not significantly different $(z=1.498 ; p=0.134)$, but the much larger deviations from the regression line in the L7-PP2B mice in combination with the longer time required to reach high performance levels clearly confirmed that learning was affected in L7-PP2B mice. The differences in learning strategies were characterized by the changes in the $d^{\prime}$ (WT vs L7-PP2B, $p=$ 0.001; Fig. 6D). These curves illustrated the superior ability of WT mice compared with L7-PP2B mutants to discriminate between go and no-go trials, and act accordingly. When the same analysis was performed for the $500 \mathrm{~ms}$ localization task, which was rapidly learned, the averages of the WT and L7-PP2B performers were already mostly in the "green area," indicating good performance, from the first session onward (Fig. 6E). Still, here too, the L7-PP2B performers showed a clear drop in performance during the second session of the 500 ms task.

\section{Purkinje cell activity during object localization}

If the differences in learning ability for whisker-based object localization between WT and L7-PP2B are indeed due to differences in intrinsic and synaptic potentiation of Purkinje cells, one can expect differences in the activity of these cells among the two genotypes. We therefore recorded the single-unit activity of Purkinje cells at the end of the localization task in ipsilateral crus 1 and crus 2, which are involved both in whisking (Axelrad and Crepel, 1977; Bosman et al., 2010) and licking (Bryant et al., 2010). To compare Purkinje cell activity during the trial with baseline activity, we divided the recordings into trial and intertrial periods. We considered the interval between the end of the (second) horizontal movement and the start of the (first) horizontal movement of the next trial the intertrial period, and the interval between the start of the upward vertical movement until the end of the downward vertical movement the trial period (Fig. 3A).

First, we characterized the simple spike firing and the complex spike firing during the intertrial periods. In line with the findings by Schonewille et al. (2010) for the vestibulocerebellum, the rate of simple spike firing was similar between WT and L7-PP2B Purkinje cells [WT cells $(n=24): 60.23 \pm 4.65 \mathrm{~Hz}$; L7-PP2B cells 
$(n=25): 55.36 \pm 3.31 \mathrm{~Hz} ; p=0.398)$, but the local variation in simple spike firing (CV2 WT vs L7-PP2B: $0.490 \pm 0.027$ vs $0.275 \pm 0.026 ; p<0.001)$ as well as the complex spike firing rate (WT vs L7-PP2B: $1.35 \pm 0.06$ vs $1.00 \pm 0.08 \mathrm{~Hz} ; p=0.002$ ) were significantly reduced in L7-PP2B Purkinje cells (Fig. 7C-E, left panels).

Next, we compared Purkinje cell activity between the trial and intertrial periods. WT Purkinje cells showed a moderate, but consistent, net increase in simple spike firing (intertrial interval: $60.23 \pm 4.66 \mathrm{~Hz}$; trial: $62.72 \pm 4.74 \mathrm{~Hz} ; p=0.004$, Wilcoxon matched-pairs test; Fig. 7C, top). In contrast, L7-PP2B Purkinje cells did not show such an increased simple spike firing (intertrial interval: $55.36 \pm 3.31 \mathrm{~Hz}$; trial: $55.54 \pm 3.32 \mathrm{~Hz} ; p=0.853$, Wilcoxon matched-pairs test; Fig. $7 C$, bottom). Thus, as might be predicted, the net increase in simple spike firing observed in WT mice is not observed in trained mice in the absence of intrinsic and synaptic potentiation of their Purkinje cells. In line with the occurrence of sensory input, the simple spike CV2 was increased both in WT and in L7-PP2B Purkinje cells, indicating that these Purkinje cells were indeed involved in the behavioral task (WT cells: intertrial interval, $0.490 \pm 0.027$; trial, $0.507 \pm 0.024 ; p=$ 0.021; L7-PP2B: intertrial interval, $0.275 \pm 0.026$; trial, $0.292 \pm$ $0.025 ; p<0.001$, Wilcoxon matched-pairs tests). The complex spike activity of WT mice and L7-PP2B mutants also both showed prominent changes between trial and intertrial periods, but these changes moved into opposite directions (Fig. $7 E$ ). In WT mice, the complex spike firing rate increased (intertrial interval vs trial: $1.35 \pm 0.06$ vs $1.50 \pm 0.07 \mathrm{~Hz} ; p=0.002$ ), whereas in L7-PP2B it decreased (intertrial interval vs trial: $1.00 \pm 0.08$ vs $0.79 \pm 0.08 \mathrm{~Hz} ; p<0.001$, Wilcoxon matched-pairs tests). We conclude that Purkinje cells in both WT and L7-PP2B mice were probably involved in the object localization task, since both groups of Purkinje cells showed an increased variability in simple spike firing. Yet, trained WT mice reacted with a net increase in both simple spike and complex spike firing, whereas the L7-PP2B mice did not. We expect that such a difference in Purkinje cell activity, which appears to be well in line with a lack of potentiation in the L7-PP2B mice, may cause changes in the output of the cerebellar nuclei that can in turn affect cerebral cortical processing via the thalamus.

\section{Discussion}

In the current study, we showed that L7-PP2B mice, which suffer from impaired intrinsic plasticity and synaptic potentiation of their Purkinje cells (Schonewille et al., 2010), exhibited learning deficits during a whisker-based object localization task. Not only were fewer L7-PP2B mice able to learn the task at long response windows, the ones that did needed more time, and the finetuning of the precise timing of their learned responses was especially deficient at short response windows. Moreover, L7-PP2B mice showed deficits in maintaining the hit rate while reducing false alarms, and their learning trajectory was considerably noisier. Finally, we showed that Purkinje cells in WT mice, but not in L7-PP2B mice, showed a net increase in firing during trials in trained mice, which further substantiates the possibility that the cerebellum is involved in learning of this whisker-based object localization task.

\section{Can the observed learning deficits be explained by motor, sensory, and/or developmental aberrations?}

Even though L7-PP2B mice do not show overt signs of motor ataxia (Schonewille et al., 2010), in principle they might suffer from small deficits in motor performance during licking and/or whisking behavior, since both types of behavior have neural correlates in the cerebellum (Lang et al., 2006; Bosman et al., 2010; Bryant et al., 2010). We therefore first investigated licking and whisking behavior of freely moving and head-fixed WT and L7PP2B mice. In line with the literature (Horowitz et al., 1977; Wiesenfeld et al., 1977; Yamamoto et al., 1982), the licking behavior was dominated by $\sim 8 \mathrm{~Hz}$ rhythmic tongue movements for both WT and L7-PP2B. Moreover, the variations in lick rhythmicity, which can depend on contextual parameters (Weijnen, 1998) such as those associated with the various stages of learning used here, occurred at an equal level in WT and L7-PP2B mice. Likewise, we recorded free whisking behavior in head-restrained mice and found that WT and L7-PP2B mice showed bouts of rhythmic whisking at comparable frequencies, that both WT and L7-PP2B mice scanned the whole area within reach of their whiskers, and that they both actively whisked during the insertion and presence of the stimulus bar in all trials tested. These control data are particularly relevant as object localization in the horizontal dimension requires active exploratory whisking (Knutsen et al., 2006), which, indeed, has been shown to typically occur in healthy mice at frequencies of 5-15 Hz (Berg and Kleinfeld, 2003; Cao et al., 2012).

It is, in principle, also possible that the localization deficits in L7-PP2B mice reflected impairments in cerebellar sensory processing rather than motor or cognitive deficits (Hartmann and Bower, 2001). We adapted our paradigm by beginning training of both genotypes with an association task. This allowed a baseline performance measure to test whether both groups not only whisked equally well, but also responded well to sensory stimulation. We found these initial learning curves and responses to stimuli to be similar in both genotypes in this task. Moreover, at the subsequent go and no-go trial testing (Fig. 4), L7-PP2B performers were able to reach criteria (albeit more slowly), and showed similar performance levels, indicating an ability to carry out the necessary responses to sensory stimuli.

Finally, since PP2B and Cre expressions are affected from early on in the L7-PP2B mutants, it is possible that their learning deficits in the whisker-based localization task result from aberrations in development rather than acute ongoing defects in cerebellar plasticity. If present at all, these potentially negative effects are probably relatively mild, since developmental compensation usually rescues negative confounders (Wulff et al., 2009), and since our electrophysiological recordings showed that the acute deficits in Purkinje cell activity of adult L7-PP2B mutants are in line with their putative deficits in potentiation and, thereby, in learning deficits. Together, we conclude that L7-PP2B mice do not show overt abnormalities in rhythmicity, frequency, or amplitude either of licking or whisker movements and that their learning deficits in the current whisker-based localization task are in line with the abnormalities in intrinsic plasticity and synaptic plasticity of their Purkinje cells.

\section{Potential role of cerebellum in cognitive tasks}

Over the past decade, an active debate has emerged on the potential role of the cerebellum in cognition. Supportive evidence was obtained not only in neuropsychological studies of cerebellar patients, functional imaging studies of human subjects, and tracing experiments in monkeys (Strick et al., 2009; Schmahmann, 2010; Timmann et al., 2010; Onuki et al., 2013), but also in behavioral studies of cerebellar cell-specific mutant mice, in which specific aspects of spatial navigation or repetitive behavior were affected (Burguiere et al., 2005; Rochefort et al., 2011; Tsai et al., 2012). Yet, it is not directly clear how to neutralize the argument that 
A- Inter-trial
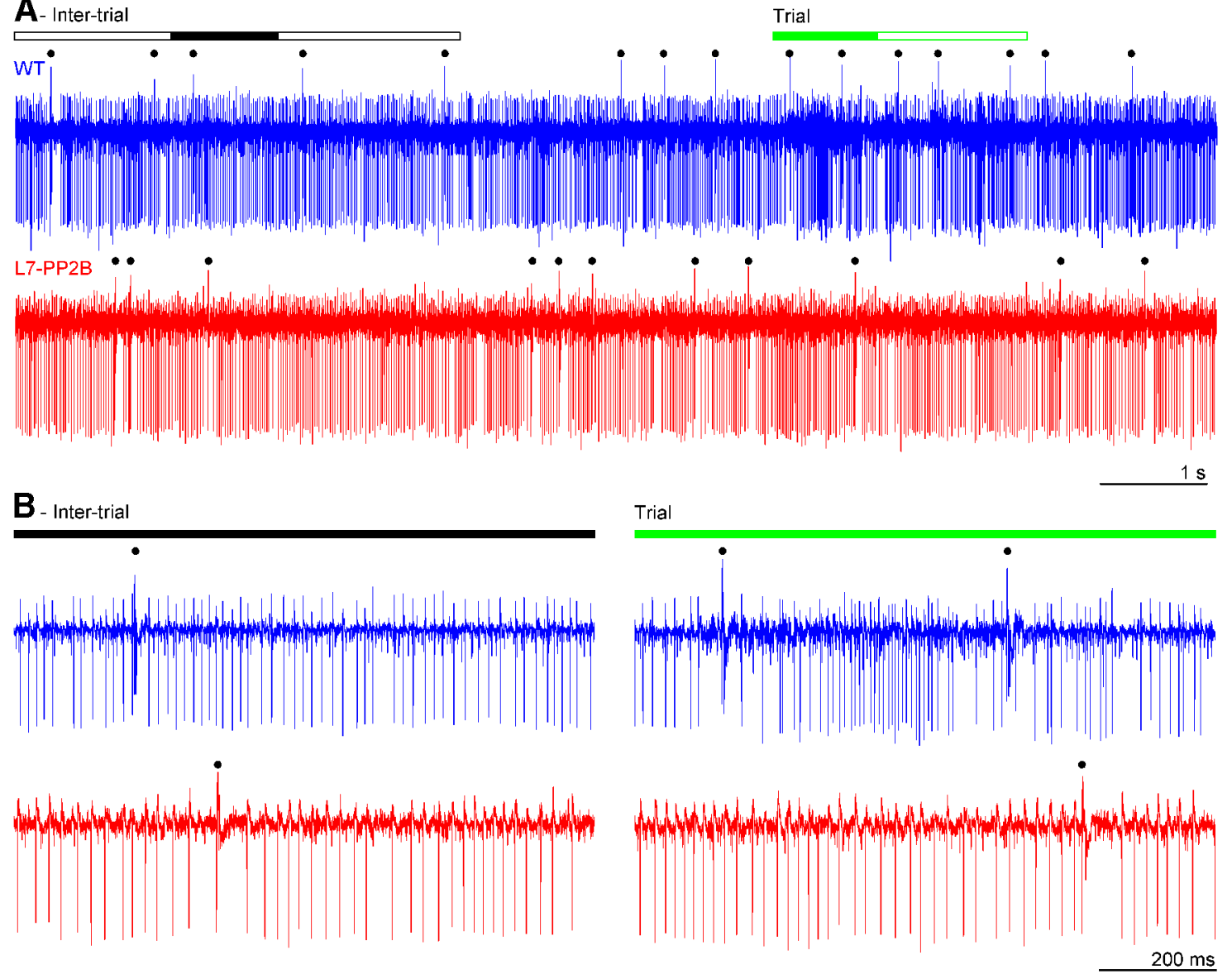

C
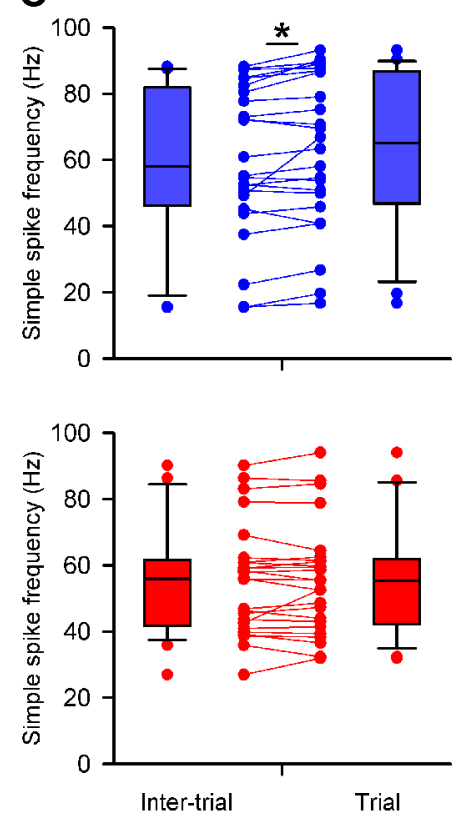

D
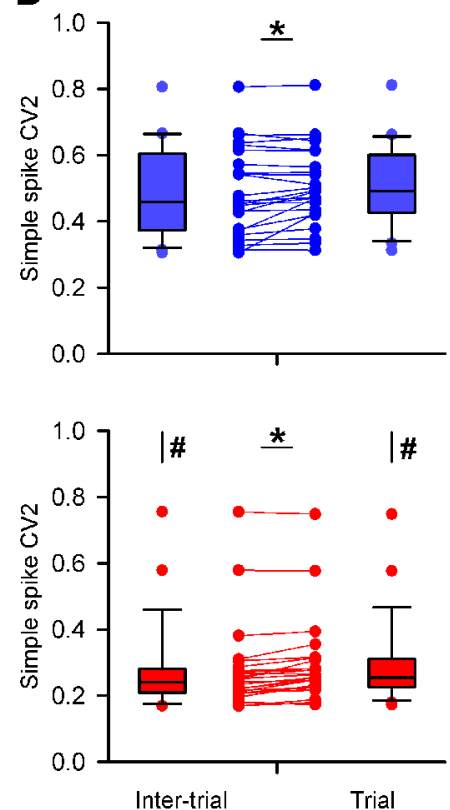

E
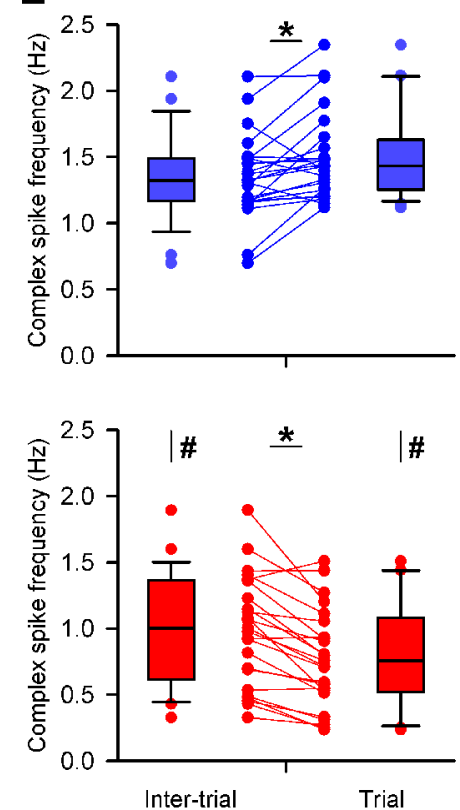

Figure 7. Differential Purkinje cell activity during the object localization task. $A$, Example single-unit traces of a WT (top) and a L7-PP2B (bottom) Purkinje cell in crus 1/crus 2 area of the cerebellum ipsilateral to the stimulus location in trained mice. The recording was divided into a trial period (consisting of the RW and the flanking periods of vertical movement of the stimulation bar) and an intertrial period (excluding the trial period and the flanking periods of horizontal movement of the stimulation bar; see Fig. $3 A$ ). The filled lines indicate the periods that are enlarged in $\boldsymbol{B}$. Complex spikes are indicated with a black dot above the trace. The other downward deflections are the simple spikes. $\boldsymbol{C}-\boldsymbol{E}$, The firing characteristics of 24 WT and 25 L7-PP2B Purkinje cells are summarized with box plots for the simple spike frequency $(\boldsymbol{C})$, simple spike CV2 $(\boldsymbol{D})$, and complex spike frequency $(\boldsymbol{E})$. Recordings were made after finishing the object localization training. The simple spike frequency was not significantly different between WT and L7-PP2B Purkinje cells. Only in WT Purkinje cells was there a modest, but significant, increase in simple spike frequency during the trial periods compared with the intertrial periods. The local variation (CV2) in simple spike firing was reduced in L7-PP2B compared with WT Purkinje cells. Yet, in both types of Purkinje cells the CV2 was increased during the trial periods. The complex spike frequency was reduced in L7-PP2B compared with WT Purkinje cells. The WT Purkinje cells showed an increase in complex spike firing during trial periods, whereas the L7-PP2B Purkinje cells showed a decrease during trial periods. \#p $<0.05$ (WT vs L7-PP2B); ${ }^{*} p<0.05$ (trial vs intertrial). 
most of these so-called cognitive effects reflect small aberrations in sensorimotor activity such as the planning of eye movements (Glickstein et al., 2009). Moreover, we recently subjected four different cerebellar cell-specific mouse mutants, including L7PP2B mice, to various cognitive tasks such as a sociability test, Morris water maze, contextual and cued fear conditioning, and open-field anxiety test, and none of the mutants showed a consistent deficit in any cognitive function (Galliano et al., 2013). However, none of these cognitive tasks included a response window or demanded precise processing in the temporal domain with a resolution of tens to hundreds of milliseconds. Given that the role of cerebellar processing in motor control has been shown to be particularly relevant when precise temporal accuracy is required (De Zeeuw et al., 2011; Onuki et al., 2013), we reasoned that this facet might also be paramount for its control in cognitive function. We therefore undertook the current whisker-based localization study in which the temporal constraints play a prominent role, while the essential role of cerebral cortex in this task has been established (Brecht, 2007; Aronoff et al., 2010; O'Connor et al., 2010a,b; Huber et al., 2012; Petreanu et al., 2012; Xu et al., 2012). Several of the present findings support the possibility that the cerebellum contributes to cognitive processing when temporal demands are critical. First, the findings that fewer L7-PP2B mice were able to learn the whisker-based localization task, that they needed more time, and that their learning trajectories were considerably noisier than in WT mice support the possibility of a general contribution of cerebellar processing in this particular cognitive task. Second, the findings that fine-tuning of the precise timing of learned responses of L7-PP2B mutants was especially deficient at short response windows and that the trained WT, but not L7-PP2B, mice showed a well timed increase in licking just at the onset of the $500 \mathrm{~ms}$ RW corroborate our hypothesis that the cerebellum contributes to cognitive processing, in particular when temporal demands are engaged.

\section{How may the cerebellum contribute to temporal precision in cognitive functions?}

Different parts of the cerebellar cortex may engage different coding schemes varying from pure rate coding to temporal coding (Heck et al., 2013). Given that during trials we observed an increase in both firing rate and variability (CV2) in the simple spike activity of WT Purkinje cells, while the firing rate of their complex spike was also increased, it is likely that both coding mechanisms play a role (De Zeeuw et al., 2011). Indeed, in L7-PP2B animals we did not observe an increase in simple spike or complex spike firing frequency in the transition from intertrial to trial periods, and the irregularity of their simple spike firing was consistently lower than that in WT animals. While changes in rate coding might directly translate into differences in modulation amplitude, and thereby the rate activity of downstream targets (De Zeeuw et al., 1995), those in temporal coding may have a prominent impact on the precise timing of the activity of downstream targets (De Zeeuw et al., 2008, 2011). Pauses in simple spike activity, which are reflected in the irregularity of firing, can translate into prominent rebound firing in the cerebellar nuclei, which in turn can trigger the initiation of movements (Witter et al., 2013). Likewise, one could imagine that rebound firing in the nuclei affects well timed initiation of activity as well as spiking coherence in areas downstream of the thalamus that are involved in cognitive tasks. For the whisker-based localization task, these may include not only the barrel cortex and whisker motor cortex (Popa et al., 2013a,b), but also the striatum (Hoshi et al., 2005; Bostan et al., 2010). Conditional discrimination tasks that require goal-directed acts are typically thought to involve the basal ganglia (Hallock et al., 2013; Nishizawa et al., 2012), which may process stop cues for cancelling actions such as during no-go trials (Schmidt et al., 2013). One could hypothesize that the differences in activity in the cerebellar microzones that use rate coding (Heck et al., 2013; Zhou et al., 2013) explain the significant difference between the number of L7-PP2B and WT mice that exhibit successful learning at the long response window phase, whereas those in the cerebellar zones that predominantly use temporal coding may explain the differences and deficits seen at the shorter RW phase and no-go trials.

\section{References}

Aronoff R, Matyas F, Mateo C, Ciron C, Schneider B, Petersen CC (2010) Long-range connectivity of mouse primary somatosensory barrel cortex. Eur J Neurosci 31:2221-2233. CrossRef Medline

Axelrad H, Crepel F (1977) Représentation sélective des vibrisses mystaciales au niveau des cellules de Purkinje du cervelet par la voie de fibres grimpantes chez le rat. C R Acad Sci Hebd Seances Acad Sci D 284:13211324. Medline

Barski JJ, Dethleffsen K, Meyer M (2000) Cre recombinase expression in cerebellar Purkinje cells. Genesis 28:93-98. CrossRef Medline

Berg RW, Kleinfeld D (2003) Rhythmic whisking by rat: retraction as well as protraction of the vibrissae is under active muscular control. J Neurophysiol 89:104-117. Medline

Bosman LW, Koekkoek SK, Shapiro J, Rijken BF, Zandstra F, van der Ende B, Owens CB, Potters JW, de Gruijl JR, Ruigrok TJ, De Zeeuw CI (2010) Encoding of whisker input by cerebellar Purkinje cells. J Physiol 588: 3757-3783. CrossRef Medline

Bosman LW, Houweling AR, Owens CB, Tanke N, Shevchouk OT, Rahmati N, Teunissen WH, Ju C, Gong W, Koekkoek SK, De Zeeuw CI (2011) Anatomical pathways involved in generating and sensing rhythmic whisker movements. Front Integr Neurosci 5:53. CrossRef Medline

Bostan AC, Dum RP, Strick PL (2010) The basal ganglia communicate with the cerebellum. Proc Natl Acad Sci U S A 107:8452-8456. CrossRef Medline

Brecht M (2007) Barrel cortex and whisker-mediated behaviors. Curr Opin Neurobiol 17:408-416. CrossRef Medline

Bryant JL, Boughter JD, Gong S, LeDoux MS, Heck DH (2010) Cerebellar cortical output encodes temporal aspects of rhythmic licking movements and is necessary for normal licking frequency. Eur J Neurosci 32:41-52. CrossRef Medline

Burguière E, Arleo A, Hojjati Mr, Elgersma Y, De Zeeuw CI, Berthoz A, Rondi-Reig L (2005) Spatial navigation impairment in mice lacking cerebellar LTD: a motor adaptation deficit? Nat Neurosci 8:1292-1294. CrossRef Medline

Cao Y, Roy S, Sachdev RN, Heck DH (2012) Dynamic correlation between whisking and breathing rhythms in mice. J Neurosci 32:1653-1659. CrossRef Medline

Carvell GE, Simons DJ (1990) Biometric analyses of vibrissal tactile discrimination in the rat. J Neurosci 10:2638-2648. Medline

De Zeeuw CI, Wylie DR, Stahl JS, Simpson JI (1995) Phase relations of Purkinje cells in the rabbit flocculus during compensatory eye movements. J Neurophysiol 74:2051-2064. Medline

De Zeeuw CI, Hoebeek FE, Schonewille M (2008) Causes and consequences of oscillations in the cerebellar cortex. Neuron 58:655-658. CrossRef Medline

De Zeeuw CI, Hoebeek FE, Bosman LW, Schonewille M, Witter L, Koekkoek SK (2011) Spatiotemporal firing patterns in the cerebellum. Nat Rev Neurosci 12:327-344. CrossRef Medline

Galliano E, Potters JW, Elgersma Y, Wisden W, Kushner SA, De Zeeuw CI, Hoebeek FE (2013) Synaptic transmission and plasticity at inputs to murine cerebellar Purkinje cells are largely dispensable for standard nonmotor tasks. J Neurosci 33:12599-12618. CrossRef Medline

Gao Z, van Beugen BJ, De Zeeuw CI (2012) Distributed synergistic plasticity and cerebellar learning. Nat Rev Neurosci 13:619-635. CrossRef Medline

Glickstein M, Strata P, Voogd J (2009) Cerebellum: history. Neuroscience 162:549-559. CrossRef Medline

Grodd W, Hülsmann E, Lotze M, Wildgruber D, Erb M (2001) Sensorimotor mapping of the human cerebellum: fMRI evidence of somatotopic organization. Hum Brain Mapp 13:55-73. CrossRef Medline 
Hallock HL, Arreola AC, Shaw CL, Griffin AL (2013) Dissociable roles of the dorsal striatum and dorsal hippocampus in conditional discrimination and spatial alternation T-maze tasks. Neurobiol Learn Mem 100:108116. CrossRef Medline

Hansel C, Linden DJ, D’Angelo E (2001) Beyond parallel fiber LTD: the diversity of synaptic and non-synaptic plasticity in the cerebellum. Nat Neurosci 4:467-475. Medline

Hartmann MJ, Bower JM (2001) Tactile responses in the granule cell layer of cerebellar folium crus IIa of freely behaving rats. J Neurosci 21:35493563. Medline

Hartmann MJ (2009) Active touch, exploratory movements, and sensory prediction. Integr Comp Biol 49:681-690. CrossRef Medline

Hayar A, Bryant JL, Boughter JD, Heck DH (2006) A low-cost solution to measure mouse licking in an electrophysiological setup with a standard analog-to-digital converter. J Neurosci Methods 153:203-207. CrossRef Medline

Heck DH, De Zeeuw CI, Jaeger D, Khodakhah K, Person AL (2013) The neuronal code(s) of the cerebellum. J Neurosci 33:17603-17609. CrossRef Medline

Horowitz GP, Stephan FK, Smith JC, Whitney G (1977) Genetic and environmental variability in lick rates of mice. Physiol Behav 19:493-496. CrossRef Medline

Hoshi E, Tremblay L, Féger J, Carras PL, Strick PL (2005) The cerebellum communicates with the basal ganglia. Nat Neurosci 8:1491-1493. CrossRef Medline

Huber D, Gutnisky DA, Peron S, O'Connor DH, Wiegert JS, Tian L, Oertner TG, Looger LL, Svoboda K (2012) Multiple dynamic representations in the motor cortex during sensorimotor learning. Nature 484:473-478. CrossRef Medline

Ito M (2001) Cerebellar long-term depression: characterization, signal transduction, and functional roles. Physiol Rev 81:1143-1195. Medline

Kleinfeld D, Deschênes M (2011) Neuronal basis for object location in the vibrissa scanning sensorimotor system. Neuron 72:455-468. CrossRef Medline

Knutsen PM, Pietr M, Ahissar E (2006) Haptic object localization in the vibrissal system: behavior and performance. J Neurosci 26:8451-8464. CrossRef Medline

Lang EJ, Sugihara I, Llinás R (2006) Olivocerebellar modulation of motor cortex ability to generate vibrissal movements in rat. J Physiol 571:101120. CrossRef Medline

Nishizawa K, Fukabori R, Okada K, Kai N, Uchigashima M, Watanabe M, Shiota A, Ueda M, Tsutsui Y, Kobayashi K (2012) Striatal indirect pathway contributes to selection accuracy of learned motor actions. J Neurosci 32:13421-13432. CrossRef Medline

O'Connor DH, Clack NG, Huber D, Komiyama T, Myers EW, Svoboda K (2010a) Vibrissa-based object localization in head-fixed mice. J Neurosci 30:1947-1967. CrossRef Medline

O'Connor DH, Peron SP, Huber D, Svoboda K (2010b) Neural activity in barrel cortex underlying vibrissa-based object localization in mice. Neuron 67:1048-1061. CrossRef Medline

Onuki Y, Van Someren EJ, De Zeeuw CI, Van der Werf YD (2013) Hippocampal-cerebellar interaction during spatio-temporal prediction. Cereb Cortex. Advance online publication. Retrieved January 2, 2014. doi:10.1093/cercor/bht221. CrossRef Medline

Perkon I, Kosir A, Itskov PM, Tasic J, Diamond ME (2011) Unsupervised quantification of whisking and head movement in freely moving rodents. J Neurophysiol 105:1950-1962. CrossRef Medline

Petreanu L, Gutnisky DA, Huber D, Xu NL, O’Connor DH, Tian L, Looger L, Svoboda K (2012) Activity in motor-sensory projections reveals distributed coding in somatosensation. Nature 489:299-303. CrossRef Medline

Popa T, Velayudhan B, Hubsch C, Pradeep S, Roze E, Vidailhet M, Meunier S,
Kishore A (2013a) Cerebellar processing of sensory inputs primes motor cortex plasticity. Cereb Cortex 23:305-314. CrossRef Medline

Popa D, Spolidoro M, Proville RD, Guyon N, Belliveau L, Léna C (2013b) Functional role of the cerebellum in gamma-band synchronization of the sensory and motor cortices. J Neurosci 33:6552-6556. CrossRef Medline

Rochefort C, Arabo A, André M, Poucet B, Save E, Rondi-Reig L (2011) Cerebellum shapes hippocampal spatial code. Science 334:385-389. CrossRef Medline

Schmahmann JD (2010) The role of the cerebellum in cognition and emotion: personal reflections since 1982 on the dysmetria of thought hypothesis, and its historical evolution from theory to therapy. Neuropsychol Rev 20:236-260. CrossRef Medline

Schmidt R, Leventhal DK, Mallet N, Chen F, Berke JD (2013) Canceling actions involves a race between basal ganglia pathways. Nat Neurosci 16:1118-1124. CrossRef Medline

Schonewille M, Belmeguenai A, Koekkoek SK, Houtman SH, Boele HJ, van Beugen BJ, Gao Z, Badura A, Ohtsuki G, Amerika WE, Hosy E, Hoebeek FE, Elgersma Y, Hansel C, De Zeeuw CI (2010) Purkinje cell-specific knockout of the protein phosphatase PP2B impairs potentiation and cerebellar motor learning. Neuron 67:618-628. CrossRef Medline

Shin SL, Hoebeek FE, Schonewille M, De Zeeuw CI, Aertsen A, De Schutter E (2007) Regular patterns in cerebellar Purkinje cell simple spike trains. PLoS One 2:e485. CrossRef Medline

Strick PL, Dum RP, Fiez JA (2009) Cerebellum and nonmotor function. Annu Rev Neurosci 32:413-434. CrossRef Medline

Timmann D, Drepper J, Frings M, Maschke M, Richter S, Gerwig M, Kolb FP (2010) The human cerebellum contributes to motor, emotional and cognitive associative learning. A review. Cortex 46:845-857. CrossRef Medline

Tsai PT, Hull C, Chu Y, Greene-Colozzi E, Sadowski AR, Leech JM, Steinberg J, Crawley JN, Regehr WG, Sahin M (2012) Autistic-like behaviour and cerebellar dysfunction in Purkinje cell Tsc1 mutant mice. Nature 488: 647-651. CrossRef Medline

Weijnen JA (1998) Licking behavior in the rat: measurement and situational control of licking frequency. Neurosci Biobehav Rev 22:751-760. CrossRef Medline

Wiesenfeld Z, Halpern BP, Tapper DN (1977) Licking behavior: evidence of hypoglossal oscillator. Science 196:1122-1124. CrossRef Medline

Witter L, Canto CB, Hoogland TM, de Gruijl JR, De Zeeuw CI (2013) Strength and timing of motor responses mediated by rebound firing in the cerebellar nuclei after Purkinje cell activation. Front Neural Circuits 7:133. CrossRef Medline

Wulff P, Schonewille M, Renzi M, Viltono L, Sassoè-Pognetto M, Badura A, Gao Z, Hoebeek FE, van Dorp S, Wisden W, Farrant M, De Zeeuw CI (2009) Synaptic inhibition of Purkinje cells mediates consolidation of vestibulocerebellar motor learning. Nat Neurosci 12:1042-1049. CrossRef Medline

Xu NL, Harnett MT, Williams SR, Huber D, O'Connor DH, Svoboda K, Magee JC (2012) Nonlinear dendritic integration of sensory and motor input during an active sensing task. Nature 492:247-251. CrossRef Medline

Yamamoto T, Matsuo R, Fujiwara T, Kawamura Y (1982) EMG activities of masticatory muscles during licking in rats. Physiol Behav 29:905-913. CrossRef Medline

Zeng H, Chattarji S, Barbarosie M, Rondi-Reig L, Philpot BD, Miyakawa T, Bear MF, Tonegawa S (2001) Forebrain-specific calcineurin knockout selectively impairs bidirectional synaptic plasticity and working/episodiclike memory. Cell 107:617-629. CrossRef Medline

Zhou H, Lin Z, Voges K, Gao Z, Ruigrok TJ, Hoebeek FE, De Zeeuw CI, Schonewille M (2013) Cerebellar modules operate at different frequencies. Paper presented at Gordon Research Conference on the Cerebellum, August 2013, New London, NH. 